\title{
OPEN Exploration of promising optical and electronic properties of (non-polymer) small donor molecules for organic solar cells
}

\author{
Muhammad Khalid ${ }^{1}$, Muhammad Usman Khan ${ }^{2 \bowtie}$, Saeed Ahmed ${ }^{1}$, Zahid Shafiq ${ }^{3 凶,}$ \\ Mohammed Mujahid Alam ${ }^{4}$, Muhammad Imran ${ }^{4}$, Ataualpa Albert Carmo Braga ${ }^{5}$ \& \\ Muhammad Safwan Akram ${ }^{6,7 凶}$
}

Non-fullerene based organic compounds are considered promising materials for the fabrication of modern photovoltaic materials. Non-fullerene-based organic solar cells comprise of good photochemical and thermal stability along with longer device lifetimes as compared to fullerene-based compounds. Five new non-fullerene donor molecules were designed keeping in view the excellent donor properties of 3-bis(4-(2-ethylhexyl)-thiophen-2-yl)-5,7-bis(2ethylhexyl) benzo[1,2-:4,5-c']dithiophene-4,8-dione thiophene-alkoxy benzene-thiophene indenedione (BDD-IN) by end-capped modifications. Photovoltaic and electronic characteristics of studied molecules were determined by employing density functional theory (DFT) and time dependent density functional theory (TD-DFT). Subsequently, obtained results were compared with the reference molecule BDD-IN. The designed molecules presented lower energy difference $(\Delta E)$ in the range of $2.17-2.39 \mathrm{eV}$ in comparison to BDD-IN (=2.72 eV). Moreover, insight from the frontier molecular orbital (FMO) analysis disclosed that central acceptors are responsible for the charge transformation. The designed molecules were found with higher $\lambda_{\max }$ values and lower transition energies than BDD-IN molecule due to stronger end-capped acceptors. Open circuit voltage (Voc) was observed in the higher range (1.54-1.78 V) in accordance with $\mathrm{HOMO}_{\text {donor }}-\mathrm{LUMO}_{\mathrm{PC61BM}}$ by designed compounds when compared with BDD-IN $(1.28 \mathrm{~V})$. Similarly, lower reorganization energy values were exhibited by the designed compounds in the range of $\lambda_{e}\left(0.00285-0.00370 E_{h}\right)$ and $\lambda_{h}\left(0.00847-0.00802 E_{h}\right)$ than BDD-IN $\left[\lambda_{e}\left(0.00700 E_{h}\right)\right.$ and $\left.\lambda_{h}\left(0.00889 E_{h}\right)\right]$. These measurements show that the designed compounds are promising candidates for incorporation into solar cell devices, which would benefit from better hole and electron mobility.

Environmental protection is in limelight as world has seen the record number of wild fires. United Nations has declared 2021-2030 as a 'Decade on Ecosystem Restoration' and the development of alternative sources of energy is at the forefront of this effort ${ }^{1-3}$. Solar power ${ }^{4}$ based on organic solar cells (OSCs) is considered efficient renewable energy source ${ }^{5}$ to cope with the global energy and environmental crisis and have the potential to overcome the limitations of silicon based solar cells, which are being heavy, rigid and unalterable HOMO-LUMO levels. The promising features of OSCs are solution-processability, flexibility and easy fabrication ${ }^{5}$. Over $14 \%$ power conversion efficiency (PCE) has been achieved by device optimization and due to innovation in photoactive materials such as non-fullerene solar cells based on single-junction polymer ${ }^{6-8}$. Many unique advantages including simple synthesis, high reproducibility, well-defined molecular structure and so on, are offered by small molecules as compared to polymers ${ }^{9-13}$. Small molecules having A- $\pi-D-\pi-A$ type architecture incorporating two end-capped electron withdrawing units, two $\pi$ bridges that interconnect the end terminal acceptor units with central core

\footnotetext{
${ }^{1}$ Department of Chemistry, Khwaja Fareed University of Engineering \& Information Technology, Rahim Yar Khan 64200, Pakistan. ${ }^{2}$ Department of Chemistry, University of Okara, Okara 56300, Pakistan. ${ }^{3}$ Institute of Chemical Sciences, Bahauddin Zakariya University, Multan 60800, Pakistan. ${ }^{2}$ Department of Chemistry, Faculty of Science, King Khalid University, P.O. Box 9004, Abha 61413, Saudi Arabia. ${ }^{5}$ Departamento de Química Fundamental, Instituto de Química, Universidade de São Paulo, Avenida Professor LineuPrestes, 748, São Paulo 05508-000, Brazil. '5Shool of Health and Life Sciences, Teesside University, Middlesbrough TS1 3BA, UK. ${ }^{7}$ National Horizons Centre, Teesside University, Darlington DL1 1HG, UK. ${ }^{\square}$ email: usman.chemistry@ gmail.com; zahidshafiq25@hotmail.com; Safwan.akram@tees.ac.uk
} 


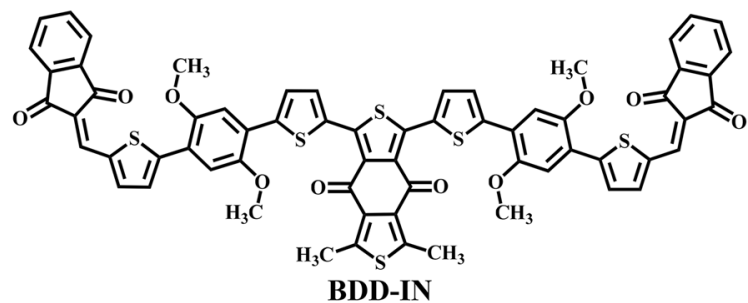

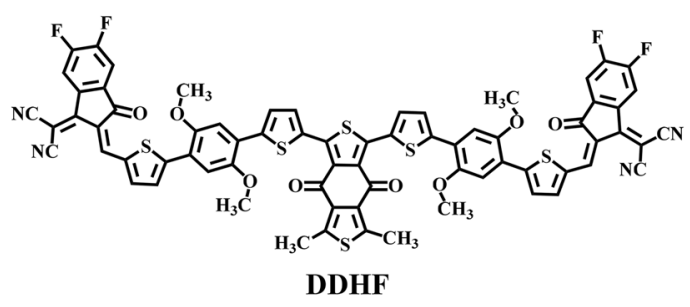

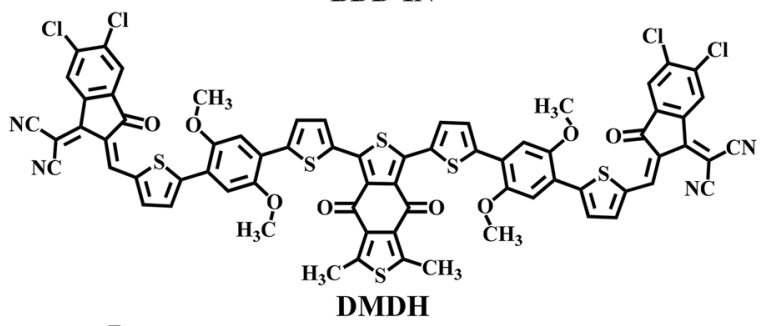

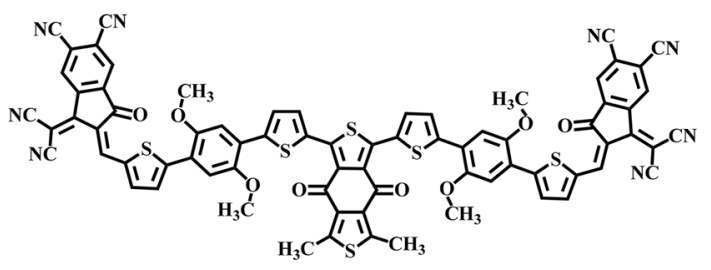

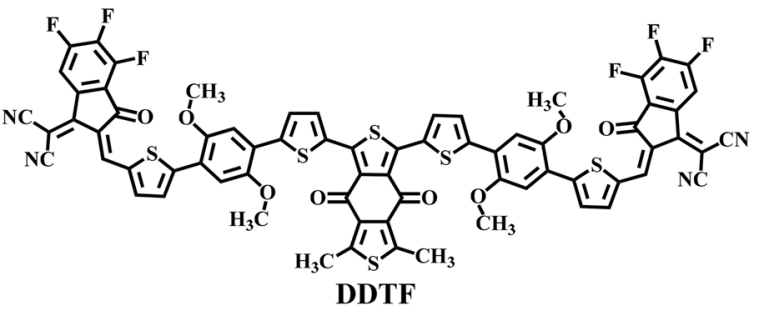

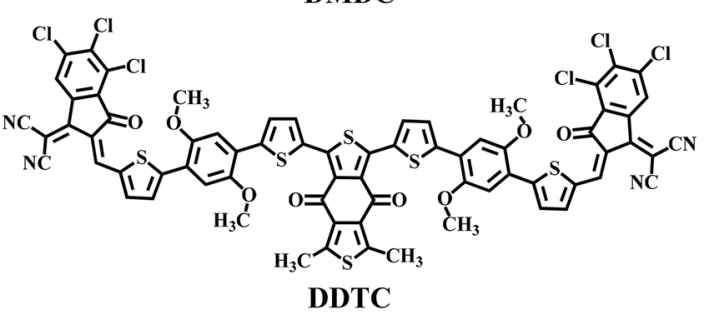

Figure 1. Structures of reference and designed compounds.

electron-donating unit offer exceptional photovoltaic performance (whether utilized as acceptors or donors) as compared to other donor-acceptor (D-A) types of small molecules ${ }^{14-16}$. For instance, Chen's group have reported DR3TSBDT comprising of end-capped 3-ethylrhodanine unit and BDT substituted dialkylthiol as central core unit with $9.95 \% \mathrm{PCE}^{17}$. A similar suit of small molecules is reported by Wei's group claiming $11.08 \% \mathrm{PCE}$ of small molecules comprising of end-capped fluorinated $1 \mathrm{H}$-indene-1,3(2H)-dione units and central core of thiophenesubstituted benzodithiophene unit ${ }^{18}$. Yan et al. in 2017 confirmed the well matched working of highly efficient donor material DR3TBDTT (DR3) with non-fullerene acceptors ${ }^{19}$. Hou's groups suggested the new wide band gap donor that incorporates a two-dimensional trialkylthienyl-substituted benzodithiophene core building for efficient non-fullerene small molecule OSCs ${ }^{20}$. It has been demonstrated that LUMO level of acceptor materials and HOMO level of donor materials govern the open-circuit voltage (Voc) values ${ }^{9,10}$. Former research specifies that these LUMO and HOMO energy levels in turn depend on the electron accepting and donating capabilities of the acceptor and donor counterparts ${ }^{21}$. Thus, it can be predicted that by enhancing electron-accepting ability of entire molecule, superior Voc could be attained when the small molecule is used as the donor materials. Small molecule donors were developed by Adhikari et al. to replace the usual polymer donors used in solvent processed solar cells, like the molecular glasses ${ }^{22}$ or the T-Shaped Indan-1,3-dione derivatives ${ }^{23}$.

The BDD is a planar group enriched with electron-withdrawing capability and therefore extensively utilized for making alternate copolymer donor materials of D-A type ${ }^{24}$. Notably, Hou's group developed PBDB-T polymer based on BDD unit is widely used in fullerene free polymer solar cells and has shown outstanding performance ${ }^{25}$. Zhang et al. described the synthesis of efficient small molecule donor BDD-IN of Acceptor2- $\pi$-Acceptor1- $\pi$ Acceptor2 $\left(A_{2}-\pi-A_{1}-\pi-A_{2}\right)$ sort incorporating of central unit BDD, thiophene-alkoxy benzene-thiophene to acts as the $\pi$-spacer, and indenedione as a terminal end-capped unit $\left(\mathrm{A}_{2}\right)$ that showed $8.70 \%$ PCE with open circuit voltage to be $0.965 \mathrm{~V}^{26}$.

End-capped modification is seen as an efficient strategy to modify the optoelectronic properties of materials used in photovoltaic materials ${ }^{27-31}$. In this manuscript, this end-capped modification strategy is utilized on $A_{2}-\pi-A_{1}-\pi-A_{2}$ type BDD-IN (dithieno[3,2-b:2',3'-d]pyran) molecule ${ }^{26}$ and five new molecules comprising of different terminal end-capped acceptor units have been designed (Fig. 1). Comprehensive in-silico studies of designed molecules (DDHF, DMDH, DMDC, DDTF and DDTC) are presented with characterization of important parameters like binding energy, transition matrix density (TDM), frontier molecular orbital (FMOs) analysis, reorganizational energy of holes and electrons, excitation energy, charge transfer analysis, open circuit voltage $\left(\mathrm{V}_{\mathrm{oc}}\right)$ and compared with BDD-IN as a reference molecule. These new non-fullerene donors (NFDs) are predicted to have improved optoelectronic properties and potential to be used in the next generation of solar cells.

\section{Results and discussion}

Reference molecule of A2- $\pi$-A1- $\pi$-A2-type recently synthesized by Zhang et al. ${ }^{26}$ is selected as BDD-IN in present quantum chemical investigation. The BDD-IN is composed of two indenedione (IN) terminal acceptor units (A2). These terminal acceptor units A2 are attached to central core unit BDD (A1) through a $\pi$-bridge (thiophene-alkoxy benzene-thiophene) units. Since, end-capped modification strategy is successfully utilized in literature to achieve the excellent photovoltaic parameters of optoelectronic materials ${ }^{32-36}$. Terminal acceptor 


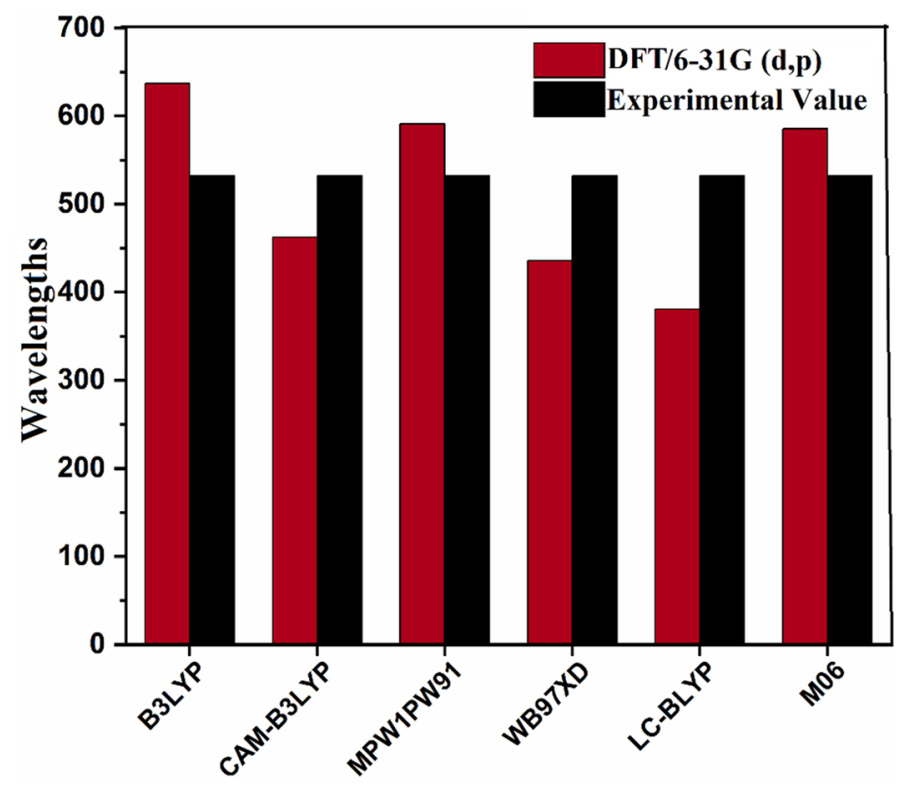

Figure 2. Graphical representation of comparison between experimentally and DFT calculated results of BDD-IN in chloroform $\left(\mathrm{CHCl}_{3}\right)$ solvent at various functionals by utilizing origin 8.5 version (https://www.origi nlab.com/). All out put files of entitled compounds were accomplished by Gaussian 09 version D.01 (https:// gaussian.com/g09citation/).

unit (A2) indenedione (IN) of BDD-IN is modified by different highly efficient end-capped acceptors like 2-(5,6-difluoro-2-methylene-3-oxo-2,3-dihydro-1H-inden-1-ylidene)malononitrile, 2-(5,6-dichloro-2-methylene-3-oxo-2,3-dihydro-1H-inden-1-ylidene)malononitrile, 1-(dicyanomethylene)-2-methylene-3-oxo-2,3-dihydro- $1 \mathrm{H}$-indene-5,6-dicarbonitrile, 2-(4,5,6-trifluoro-2-methylene-3-oxo-2,3-dihydro-1H-inden-1-ylidene) malononitrile,2-(4,5,6-trichloro-2-methylene-3-oxo-2,3-dihydro-1H-inden-1-ylidene)malononitrile. The IUPAC names and codes of designed molecules are 2,2 ((2Z,2' Z)-((5,5'-((5,5'-(5,7-dimethyl-4,8-dioxo-4,8dihydrobenzo[1,2-c:4,5-c']dithiophene-1,3-diyl)bis(thiophene-5,2-diyl))bis(2,5-dimethoxy-4, 1-phenylene)) bis(thiophene-5,2-diyl))bis(methanylylidene))bis(5,6-difluoro-3-oxo-2,3-dihydro-1H-indene-2,1-diylidene)) dimalononitrile (DDHF), 2,2'-((2Z,2'Z)-((5,5'-((5,5'-(5,7-dimethyl-4,8-dioxo-4,8-dihydrobenzo[1,2-c:4,5-c'] dithiophene-1,3-diyl)bis(thiophene-5,2-diyl))bis(2,5-dimeth oxy-4,1-phenylene))bis(thiophene-5,2-diyl)) bis(methanylylidene))bis(5,6-dichloro-3-oxo-2,3-dih ydro-1H-indene-2,1diylidene))di-malononitrile (DMDH), (2Z,2'Z)-2,2'-((5,5'-((5,5'-(5,7-dimethy 1-4,8-dioxo-4,8-dihydrobenzo[1,2-c:4,5-c'] dithiophene-1,3-diyl) bis(thiophene-5,2-diyl))bis(2,5-dimethoxy-4,1-phenylene))bis(thiophene-5,2-diyl))bis(methanylylidene)) bis(1-(dicyanomethyle ne)-3-oxo-2,3-dihydro-1H-indene-5,6-dicarbonitrile) (DMDC), 2,2'-((2Z,2'Z)-((5,5'-((5, 5'-(5,7-dimethyl-4,8-dioxo-4,8-dihydrobenzo[1,2-c:4,5-c'] dithiophene-1,3-diyl)bis(thiophene-5,2-diyl))b is(2,5dimethoxy-4,1-phenylene))bis(thiophene-5,2-diyl))bis(methanylylidene))bis(4,5,6-trifluor o-3-oxo-2,3-dih ydro$1 \mathrm{H}$-indene-2,1-diylidene))di-malononitrile (DDTF), 2,2'-((2Z,2' Z)-((5,5'-((5,5'-(5,7-dimethyl-4,8-dioxo-4,8dihydrobenzo[1,2-c:4,5-c'] dithiophene-1,3-diyl)bis(thiophene-5,2-diyl))bis(2,5-dimethoxy-4,1-phenylene)) bis(thiophene-5,2-diyl))bis(methanylylidene))bis(4,5, 6-tri-chloro-3-oxo-2,3-dihydro-1H-indene-2,1-diylidene)) di-malononitrile (DDTC). The five new compounds mentioned here as DDHF-DDTC are designed as shown in Fig. 1.

For selection of best suited functional of theory, $\lambda_{\max }$ values of BDD-IN molecule was calculated at six different functional including B3LYP/6-31G(d,p), CAM-B3LYP/6-31G(d,p), $\omega B 97 X D / 6-31 G(d, p)$, MPW1PW91/6-31G $(d, p)$, M06/6-31G (d,p) and LC-BLYP/6-31G (d, p). The $\lambda_{\max }$ values of reference molecule on these levels are observed as $636.82 \mathrm{~nm}, 462.21 \mathrm{~nm}, 591.16 \mathrm{~nm}, 435.64 \mathrm{~nm}, 380.91 \mathrm{~nm}$, and $585.49 \mathrm{~nm}$ respectively (Fig. 2). On comparing DFT computed values at different functionals with experimentally reported value of reference molecule $(532 \mathrm{~nm})^{26}$, it is apparent that results from M06/6-31G(d,p) level of theory correlate well with experimental value and can be used for further calculations of designed compounds (DDHF-DDTC) (see Fig. 2).

The optimized geometries found at true minima in potential energy surfaces are shown in Fig. 3.

Frontier molecular orbitals (FMOs) analysis. FMOs analysis is a very useful tool for the characterization of electronic and optical properties of molecules ${ }^{37}$. According to band theory, HOMO and LUMO orbitals are denoted as valence and conduction band respectively. In photovoltaic materials, FMOs energy difference $\left(\triangle \mathrm{E}=\mathrm{E}_{\mathrm{LUMO}}-\mathrm{E}_{\mathrm{HOMO}}\right)$ is considered as a hallmark of ability to carry charge $\mathrm{e}^{38-43}$. The charge carrier mobility of designed donor molecules can be improved through conjugation due to the electronic delocalization within the molecular systems. Energy of HOMO, LUMO and their difference are fully coupled with PCE of solar cells. It is also illustrated that there is dynamic stability, electron transfer characteristics, chemical softness/hardness and reactivity of the designed compounds ${ }^{44}$. FMOs study for the distribution of charges and principally the $\Delta \mathrm{E}$ 


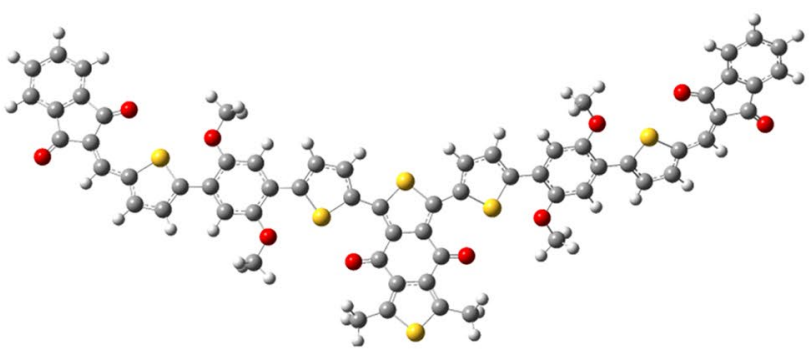

BDD-IN

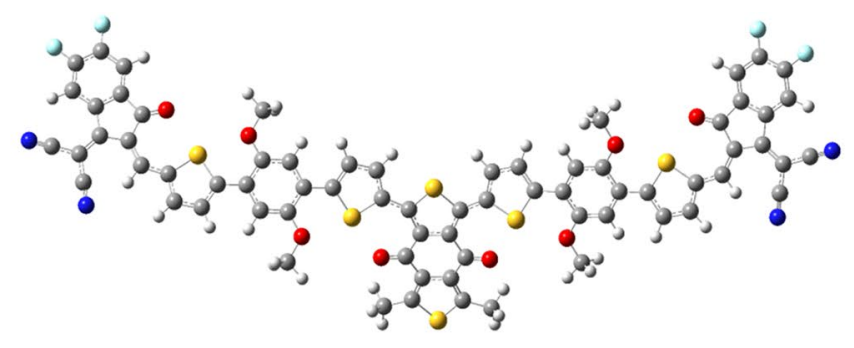

DDHF
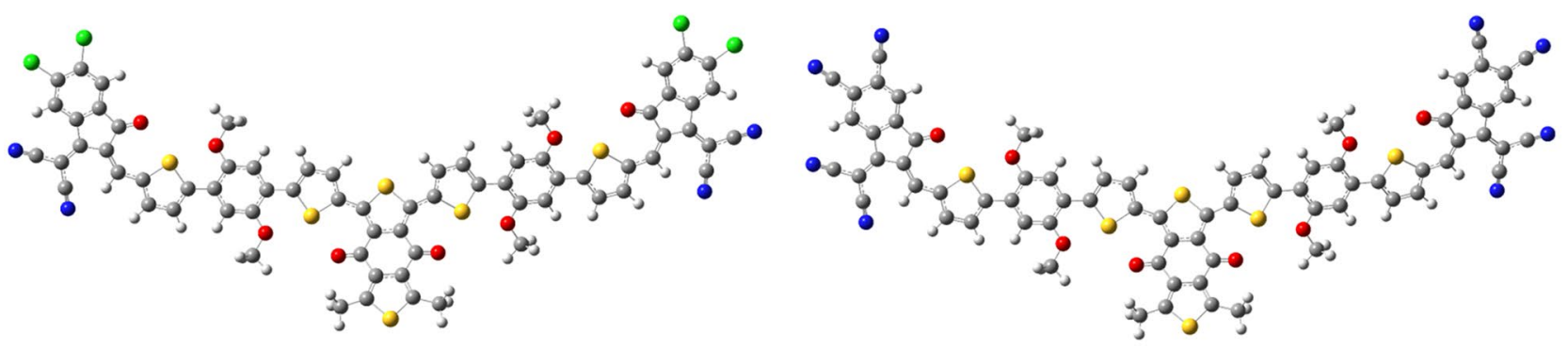

DMDH

DMDC

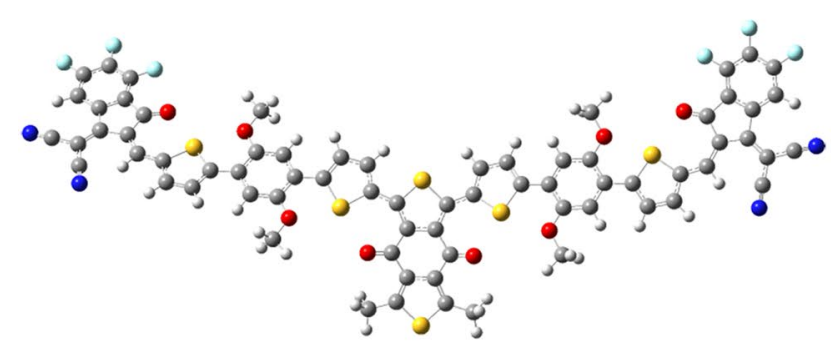

DDTF

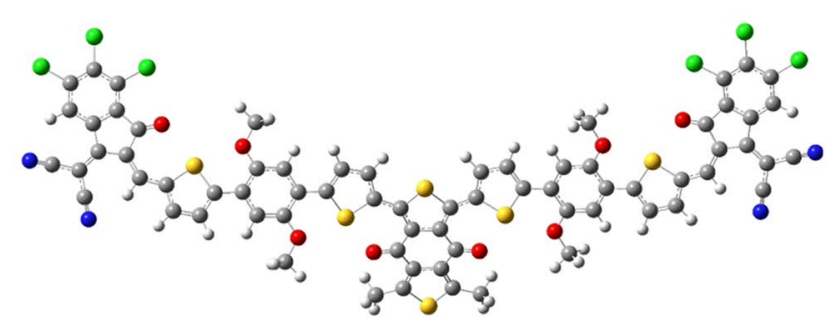

DDTC

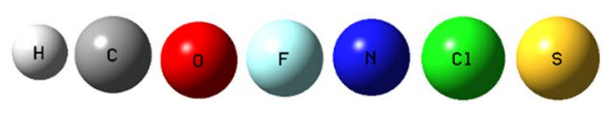

Figure 3. Optimized structures of studied compounds are made with the help of GaussView 5.0 and Gaussian 09 version D.01 (https://gaussian.com/g09citation/) Cartesian co-ordinates of all the molecules are presented in Supplementary Tables S1, S2, S3, S4, S5 and S6.

\begin{tabular}{|l|l|l|l|}
\hline Compound & HOMO & LUMO & $\Delta \mathbf{E}=\mathbf{E}_{\text {LUмо }}-\mathbf{E}_{\text {номо }}$ \\
\hline BDD-IN & -5.28 & -2.56 & 2.72 \\
\hline DDHF & -5.54 & -3.15 & 2.39 \\
\hline DMDH & -5.57 & -3.22 & 2.35 \\
\hline DMDC & -5.78 & -3.61 & 2.17 \\
\hline DDTF & -5.56 & -3.22 & 2.34 \\
\hline DDTC & -5.58 & -3.27 & 2.31 \\
\hline
\end{tabular}

Table 1. FMO energies associated with designed and reference molecules. $E$ energy, $\Delta \mathrm{E} E_{\mathrm{LUMO}}-E_{\mathrm{HOMO}}$.

between HOMO/LUMO orbitals is significant to recognize the electronic behavior and optical properties of the investigated compounds throughout the excitation process. FMOs study was performed at TD-DFT/M06/6$31 \mathrm{G}(\mathrm{d}, \mathrm{p})$ level and HOMO, LUMO energies and their difference in energy $\Delta \mathrm{E})$ that are presented in Table 1. Additionally, the pictographic representation for FMOs for BDD-IN, and designed molecules are displayed in Fig. 4.

The $\mathrm{E}_{\mathrm{HOMO}}$ and $\mathrm{E}_{\mathrm{LUMO}}$ of DMDC are less than all other molecules, signifying the better electron withdrawing effect of the four terminal cyano units of DMDC. Conversely, HOMO-LUMO values in BDD-IN were found greater as compared to the corresponding value of designed structures that predicts the lesser efficiency than the end-caped acceptors of all designed compounds. Moreover, in DMDC, the HOMO-LUMO energy levels are stable than DDHF and DMDH, which designate the significant proficiency of end-caped acceptor moieties. 

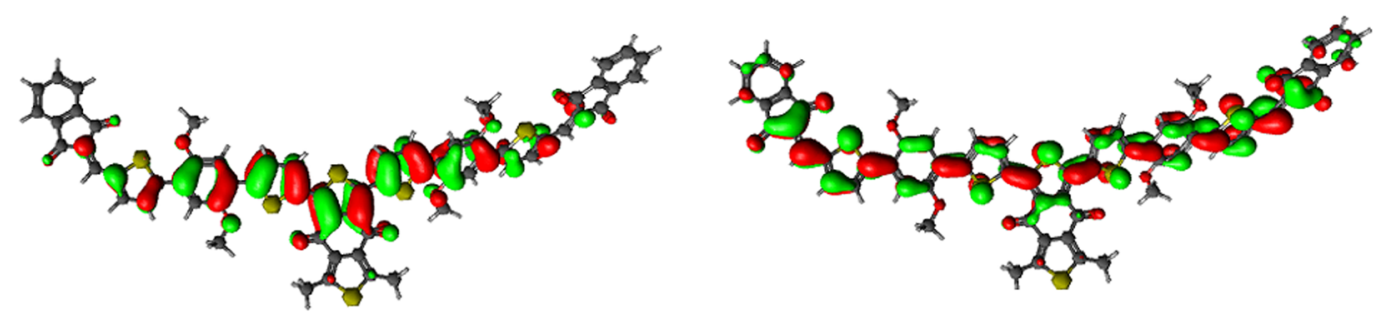

HOMO

BDD-IN

LUMO
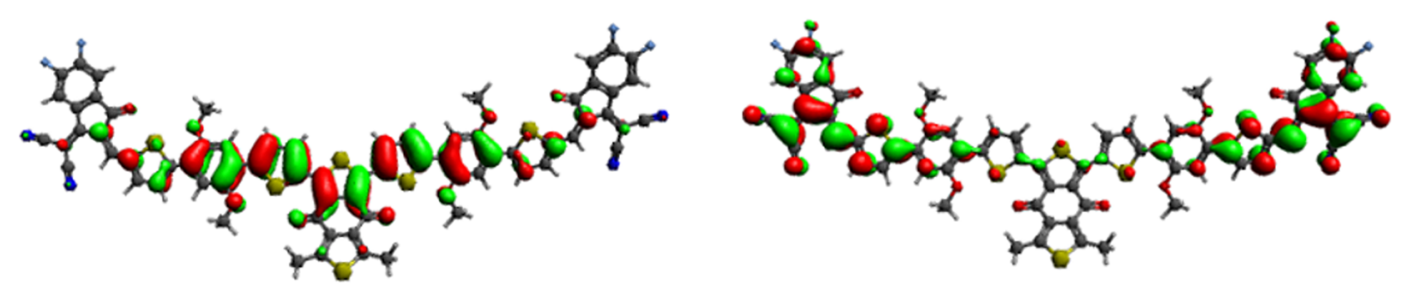

DDHF

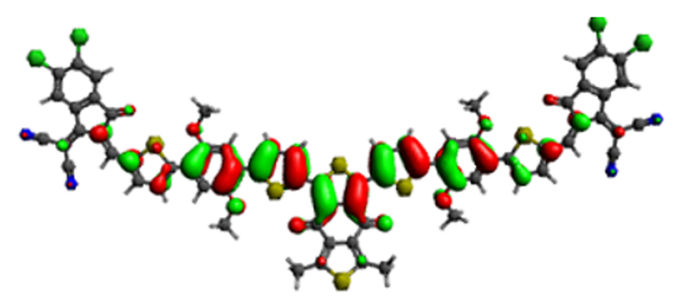

HOMO

DMDH

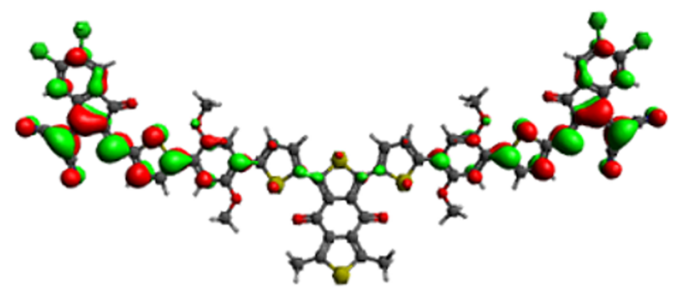

LUMO
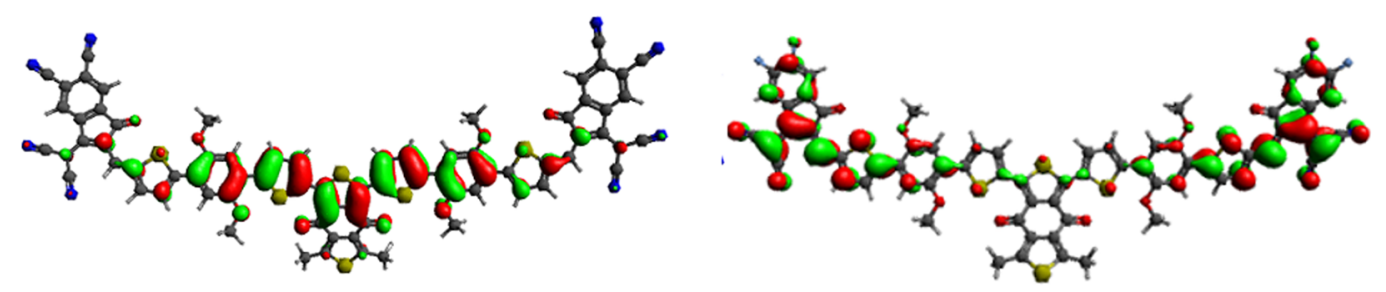

HOMO

DMDC

LUMO

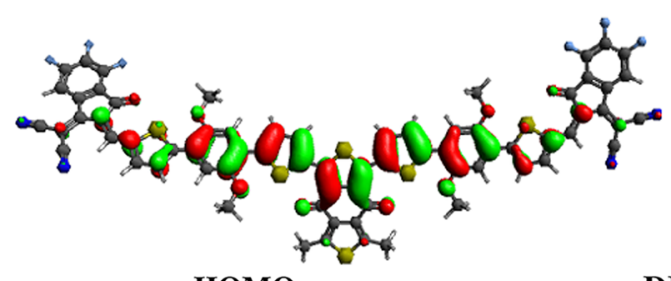

HOMO

DDTF

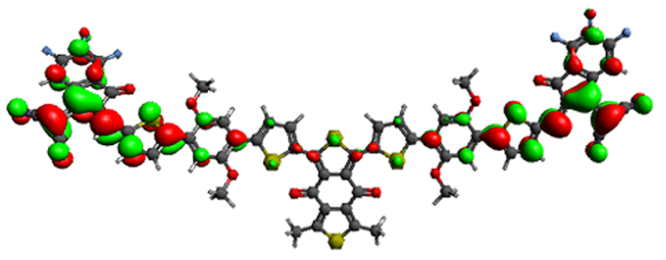

LUMO

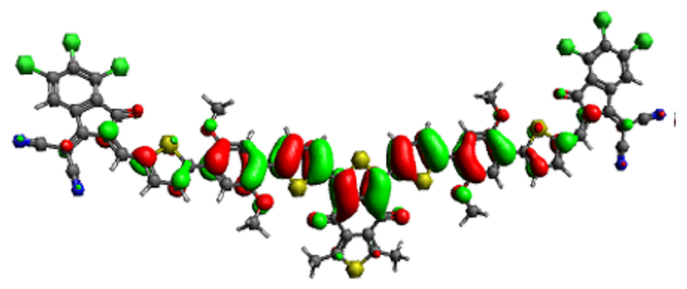

HOMO

DDTC

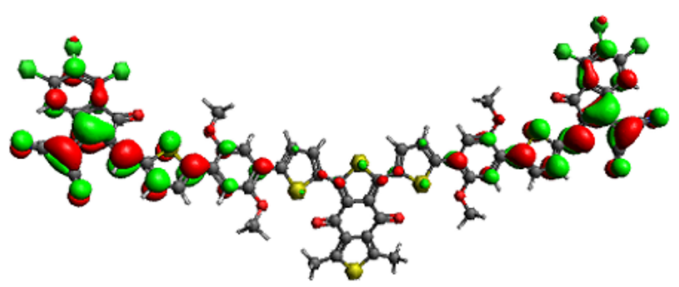

LUMO

Figure 4. Pictographic representation of FMOs for reference and designed compounds. The pictures are drawn with the help of Avogadro software, Version 1.2.0. (http://avogadro.cc/). All out put files of entitled compounds were accomplished by Gaussian 09 version D.01 (https://gaussian.com/g09citation/). 
Furthermore, HOMO-LUMO values of DDTF and DDTC were observed to be larger than DDHF and DMDH values due to the end-caped acceptors of DDTF and DDTC, respectively. Overall, the HOMO-LUMO values are found in the following reducing order: $\mathrm{BDD}-\mathrm{IN}>\mathrm{DDHF}>\mathrm{DDTF}>\mathrm{DMDH}>\mathrm{DDTC}>\mathrm{DMDC}$ and $\mathrm{BDD}-$ IN $>$ DDHF $>$ DMDH $>$ DDTF $>$ DDTC $>$ DMDC, respectively.

The $\Delta \mathrm{E}$ is another substantial means to signify the charge transformation within a molecule. The maximum $\Delta \mathrm{E}$ value $(2.72 \mathrm{eV})$ amongst all investigated molecules is seen in BDD-IN. Table 1 shows that $\Delta \mathrm{E}$ values are diminished for DMDC as compared to BDD-IN, DDHF, DMDH, DDTF and DDTC. Among designed and the reference compounds, DMDC exhibits the lowest energy gap value which could be attributed to the combined effect of extended conjugation and on better electron withdrawing effect of the four terminal cyano units present in end-capped acceptor of DMDC as compared to other compounds. The $\triangle \mathrm{E}$ result of all the studied compounds are reported in the region of 2.17-2.72 eV. As indicated in Fig. 4, the HOMO charge is propagated on the central accepter moiety and a little amount of charge is observed on the $\pi$-spacer, whereas LUMO is dispersed on the end-capped acceptor units of the studied compounds. This charge dispersion patterns show that occurrence of electrons delocalization is caused by high donor to acceptor charge transfer with the aid of $\pi$-bridging unit.

Partial density of states (P-DOS) were computed at M06/6-31G (d, p) level of DFT (Fig. 4). Figure 5 is also in accordance with the factors presented in FMOs study and along with Fig. 4, it reveals that charge is concentrated around LUMO and HOMO because of strong dragging and the electron accepting capability of terminal units. In BDD-IN, the HOMO charge density is occupied primarily on central acceptor part (A1) and $\pi$-spacer, while the LUMO is occupied completely on whole molecule except upper part of the central acceptor unit (A1) and half portion of the end-caped acceptor (A2). The HOMO charge density is completely distributed on the central acceptor part (A1) and $\pi$-spacer unit and the LUMO is distributed completely on the end-capped acceptor units A2. Overall, these charge density circulation patterns reveal that electron delocalization is happened and huge charge transferred from the central acceptor part (A1) to end-capped acceptor units A2 with the assistance of the bridge part occurred.

Optical properties. To evaluate the photo-physical responses for BDD-IN, DDHF-DDTC, TD-DFT at $\mathrm{M} 06 / 6-31 \mathrm{G}(\mathrm{dp})$ level of theory was employed to execute UV-Visible absorption spectra in $\mathrm{CHCl}_{3}$ solvent. The computed results attained from spectral analysis comprising $\lambda_{\max }$, transition energy $\left(\mathrm{E}_{\mathrm{x}}\right)$, oscillator strengths $\left(f_{o s}\right)$, and transition natures of the investigated molecules are arranged in Table 2. Absorption spectra are presented in Fig. 6 showing two absorption peaks for each studied compound representing the major and minor absorption peaks.

Maximum absorption peak $\left(\lambda_{\max }=585 \mathrm{~nm}\right)$ of BDD-IN is in good agreement with experimental $\left(\lambda_{\max }=532 \mathrm{~nm}\right)$ value as can be seen in Table 2 . The electron withdrawing groups can potentially be attributed for the red shift in $\lambda_{\max }$ values in the observed spectra. The TD-DFT based calculations also reveal that absorbance of all studied compounds is found in the visible region within the range of $666-732 \mathrm{~nm}$. The $\lambda_{\max }$ values of designed compounds are reported considerably larger and red shifted than that of BDD-IN molecule (Fig. 6). Table 2 reveals that the lowest value of $\lambda_{\max }$ is found in BDD-IN molecule among all the investigated compounds. The strong electron withdrawing capability of four F atoms and four CN groups present in end-capped unit of the compound DDHF successfully caused the red shift to $\lambda_{\max }$ value to $666 \mathrm{~nm}$ which confirms the utility of DDHF end-capped acceptor as compared to other end-capped acceptors of BDD-IN molecule which lack F and $\mathrm{CN}$ groups. Replacement of four fluorine with chlorine atoms in the end-capped acceptor of DDHF converts it to the compound DMDH. This change increases the $\lambda_{\max }$ value to $683 \mathrm{~nm}$ showing potential of DMDH over DDHF and BDD-IN molecules. Similarly, the replacement of four chloro groups with cyano groups in DMDH yields compound DMDC, where $\lambda_{\max }$ value shifts to $732 \mathrm{~nm}$, the largest $\lambda_{\max }$ value among all the designed compounds. These results confirmed the superiority of DMDC end-capped acceptor containing CN units over all other compounds. The compound DDTF where end-capped unit contains six F atoms successfully shifted the $\lambda_{\max }$ value to $679 \mathrm{~nm}$, showing that the number of fluorine atoms play their role in causing the red shift. Likewise, the replacement of six fluoro atoms with chloro groups in DDTF produced compound DDTC which also led to the successful red shift of the maximum absorption peak $\left(\lambda_{\max }\right)$ value to $692 \mathrm{~nm}$ and proved the usefulness of DDTC over DDTF molecule as well as over BDD-IN molecule. Overall, the designed compounds showed red shift of $81,98,147,94$ and $107 \mathrm{~nm}$ in comparison to that of BDD-IN molecule correspondingly. The maximum absorption peak $\left(\lambda_{\max }\right)$ for BDD-IN molecule and designed compounds is in the following escalating order: $\mathrm{BDD}-\mathrm{IN}<\mathrm{DDHF}<\mathrm{DDTF}<\mathrm{DMDH}<\mathrm{DDTC}<$ DMDC.

Excitation energy or charge transfer character exhibits valuable insights and proposes that molecules having smaller transition energy accommodate higher charge transfer capability, easy excitation between the HOMO to LUMO and possess higher PCEs. In case of BDD-IN, maximum value of excitation energy is noticed as $2.11 \mathrm{eV}$. Strong electron accepting capability of end-caped groups reduces the excitation energy in designed compounds. Hence, the calculated transition energy values show that the reference molecule BDD-IN has greater value of transition energy than the designed compounds. The excitation energy values for DDHF-DDTC are found to be $1.86,1.81,1.69,1.82$ and $1.79 \mathrm{eV}$, respectively. The lowest excitation energy is $1.69 \mathrm{eV}$ in the case of DMDC due to presence of cyano group and extended conjugation. The increasing order for excitation energy of the designed compounds agrees with the decreasing $\lambda_{\max }$ order: $\mathrm{BDD}-\mathrm{IN}>\mathrm{DDHF}>\mathrm{DDTF}>\mathrm{DMDH}>\mathrm{DDTC}>\mathrm{DMDC}$. The smallest transition energy of DMDC and the highest $\lambda_{\max }$ value make it a suitable candidate to be used in solar cells due to the better optoelectronic properties. The previous examination concludes that all the designed molecules containing higher $\lambda_{\max }$ and lower transition energy values possess good potential of optoelectronic properties than that of BDD-IN molecule. Hence, all designed compounds especially DMDC is predicted to be capable of being utilized as an electron donating molecule in OSCs applications. 

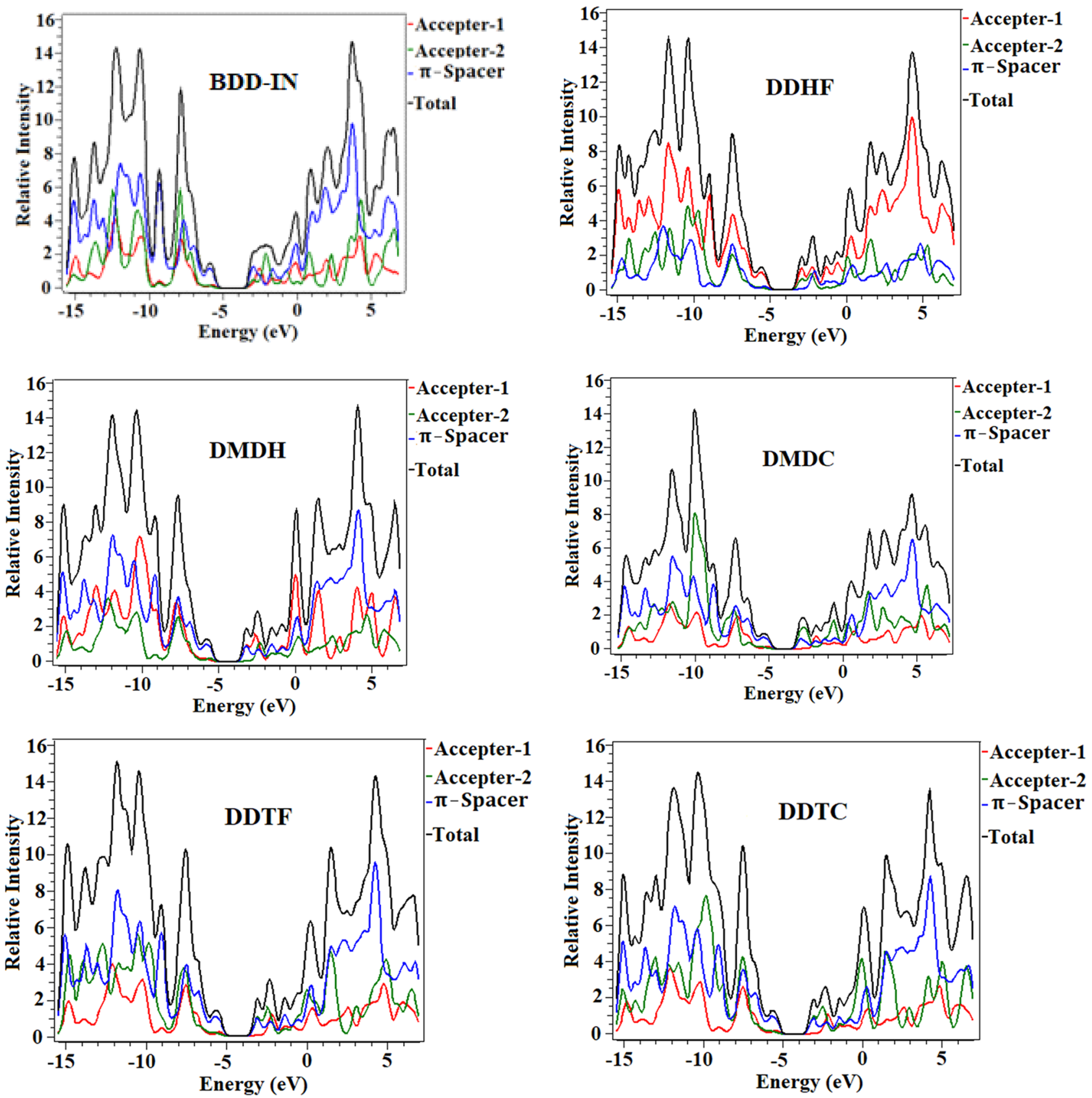

Figure 5. Graphical representation of the density of states (DOS) for BDD-IN, DDHF-DDTC drawn by utilizing PyMOlyze 1.1 version (https://sourceforge.net/projects/pymolyze/). All out put files of entitled compounds were accomplished by Gaussian 09 version D.01 (https://gaussian.com/g09citation/).

\begin{tabular}{|l|l|l|l|l|l|}
\hline Compound & DFT $\lambda(\mathbf{n m})$ & Exp. $\lambda(\mathbf{n m})$ & $\mathbf{E}(\mathbf{e V})$ & $\boldsymbol{f}$ & MO contributions \\
\hline BDD-IN & 585 & 532 & 2.11 & 3.2 & $\mathrm{H}-1 \rightarrow \mathrm{L}+1(11 \%), \mathrm{H} \rightarrow \mathrm{L}(80 \%)$ \\
\hline DDHF & 666 & & 1.86 & 3.2 & $\mathrm{H}-1 \rightarrow \mathrm{L}+1(12 \%), \mathrm{H} \rightarrow \mathrm{L}(80 \%)$ \\
\hline DMDH & 683 & & 1.81 & 3.2 & $\mathrm{H}-1 \rightarrow \mathrm{L}+1(12 \%), \mathrm{H} \rightarrow \mathrm{L}(80 \%)$ \\
\hline DMDC & 732 & & 1.69 & 2.6 & $\mathrm{H}-1 \rightarrow \mathrm{L}+1(10 \%), \mathrm{H} \rightarrow \mathrm{L}(82 \%)$ \\
\hline DDTF & 679 & & 1.82 & 3.0 & $\mathrm{H}-1 \rightarrow \mathrm{L}+1(12 \%), \mathrm{H} \rightarrow \mathrm{L}(80 \%)$ \\
\hline DDTC & 692 & & 1.79 & 3.0 & $\mathrm{H}-1 \rightarrow \mathrm{L}+1(12 \%), \mathrm{H} \rightarrow \mathrm{L}(81 \%)$ \\
\hline
\end{tabular}

Table 2. Wavelength, excitation energy and oscillator strength of studied compounds. $f=$ oscillator strength, $\mathrm{MO}=$ molecular orbital, $\mathrm{H}=\mathrm{HOMO}, \mathrm{L}=\mathrm{LUMO}$. 


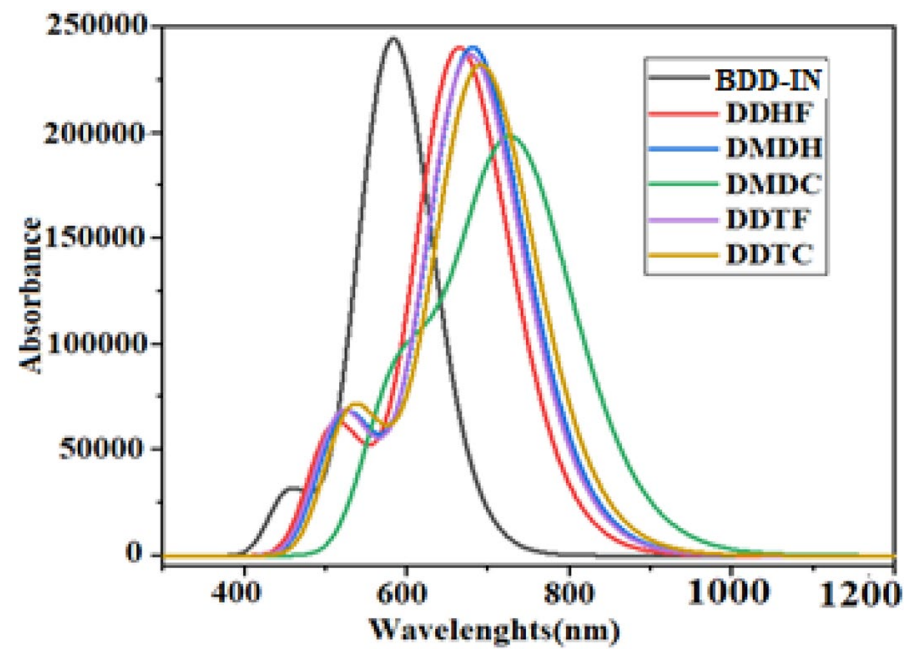

Figure 6. Graphical representation of UV-Visible absorption spectra of studied compounds.

\begin{tabular}{|l|l|l|}
\hline Molecule & $\lambda_{\boldsymbol{e}}\left(\boldsymbol{E}_{\boldsymbol{h}}\right)$ & $\boldsymbol{\lambda}_{\boldsymbol{h}}\left(\boldsymbol{E}_{\boldsymbol{h}}\right)$ \\
\hline BDD-IN & 0.00700 & 0.00889 \\
\hline DDHF & 0.00370 & 0.00826 \\
\hline DMDH & 0.00333 & 0.00802 \\
\hline DMDC & 0.00285 & 0.00847 \\
\hline DDTF & 0.00343 & 0.00824 \\
\hline DDTC & 0.00311 & 0.00820 \\
\hline
\end{tabular}

Table 3. Reorganization energy of BDD-IN, DDHF-DDTC molecules. $\lambda_{\mathrm{e}}$ : Rate of transfer of electrons, $\lambda_{\mathrm{h}}$ : rate of transfer of hole.

Reorganization energy (RE). Reorganization energy is a fundamental characteristic to correlate the molecular structure with charge transportation ability of compounds which can help to design the best candidates for photovoltaic applications. The charge transfer capability and reorganization energy are inversely proportional to each other. To evaluate the transportability of charge by designed molecules: DDHF, DMDH, DMDC, DDTF and DDTC, the reorganization n energies were calculated by utilizing Eqs. (3) and (4). Reorganization energy of all studied compounds was computed at the M06/6-31G (d, p) level of theory (Table 3).

The anionic and cationic geometries indicate the transformation of electron and hole towards acceptor from the donor molecule. Reorganization energy (RE) can be utilized to compute the charger transfer (CT) between the electron donating and accepting moieties. This energy is categorized in two segments: internal reorganization energy $\left(\operatorname{RE}-\lambda_{\text {int. }}\right)$ and external RE $\left(\boldsymbol{\lambda}_{\text {ext. }}\right)$. Both $\boldsymbol{\lambda}_{\text {ext. }}$ and $\boldsymbol{\lambda}_{\text {int. }}$ specifies the polarization effect on the external environmental and the rapid alterations in the internal geometry, respectively. For this manuscript, the environmental variations have not been considered as they have little effect and only $\boldsymbol{\lambda}_{\text {int. }}$ is considered. The value of $\boldsymbol{\lambda}_{\mathrm{e}}$ for DDHF $\left(0.0037 E_{h}\right)$ was found to be less than BDD-IN (0.0070) signifying the dominant electron transfer rate for DDHF as compared to BDD-IN. Likewise, the value of $\lambda_{\mathrm{e}}$ for DMDH $\left(0.00333 E_{h}\right)$ was noticeably smaller than BDD-IN $\left(0.0070 E_{h}\right)$ and DDHF implying that two terminal chlorine groups work efficiently to tune the intra molecular charge transfer as compared to two fluorines in DDHF. Due to cyano groups modification in DMDC, least value of electron reorganization energy was found to be $0.00285 E_{h}$ among all the studied compounds indicating the best efficiency of cyano groups as compared to other functional groups present in terminal acceptors. The $\lambda_{\mathrm{e}}$ for DDTF and DDTC were also found smaller than the reference molecule due to end-capped modifications.

The highest $\lambda_{\mathrm{h}}$ value of all investigated compounds was noted and compared with BDD-IN molecule. As discussed, the reasons for reduction in electron reorganization energy, hole reorganization energy is also abridged in designed compounds due to end-capped modifications of different functional units. The $\lambda_{\mathrm{h}}$ values of designed compounds DDHF-DDTC are 0.00826, 0.00802, 0.00847, 0.00824 and $0.00820 E_{h}$ respectively that are much smaller as compared to that of BDD-IN $\left(0.00889 E_{h}\right)$ and this reveals that designed compounds have a greater rate of transformation of holes in comparison to BDD-IN molecule. Overall, the values of $\lambda_{\mathrm{e}}$ are smaller as compared to $\lambda_{\mathrm{h}}$ which proposes that these compounds are inspiring candidates for transfer of electrons.

Open circuit voltage (Voc). Voc is significant to illustrate the execution of OSCs ${ }^{45}$ and reveals the highest value of current that can be taken away from an optical device in this context ${ }^{46}$. It is at the point of maximum 

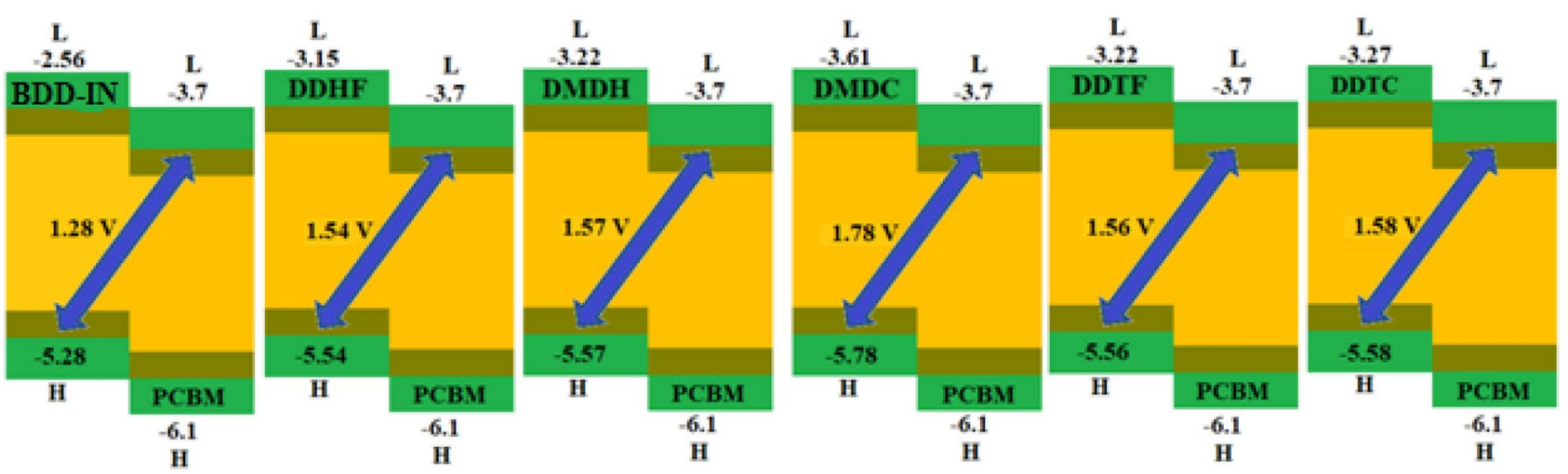

Figure 7. Graphical representation of Voc for studied compounds. All out put files of the designed compounds were accomplished by Gaussian 09 version D.01 (https:/gaussian.com/g09citation/).

voltage that can be gained at zero current value from any device. Voc depends on numerous features: external fluorescence proficiency, charge carrier recombination, light source, temperature of OSCs device, light intensity, and different environmental features. Principally, Voc relies on the saturation current and light generation that assists the recombination in the devices. Voc is approximately proportional to $\Delta \mathrm{E}$ of donor and acceptor molecules corresponding to $\mathrm{HOMO}_{\text {donor }}-\mathrm{LUMO}_{\mathrm{PC} 61 \mathrm{BM}}$ energies. In the current quantum chemical evaluation, Voc values are calculated by utilizing acceptor molecule $\left(\mathrm{PC}_{61} \mathrm{BM}\right)$. The $\mathrm{Voc}$ of $\mathrm{PC}_{61} \mathrm{BM}$ is variable and depends completely on the electron donating compound. Theoretically the calculated results of Voc for the OSCs have been with the aid of Eq. (1), established by Scharber and his co-workers ${ }^{47}$.

$$
\operatorname{Voc}=\left(\left|\mathrm{E}_{\mathrm{HOMO}}^{\mathrm{D}}\right|-\left|\mathrm{E}_{\mathrm{LUMO}}^{\mathrm{A}}\right|\right)-0.3
$$

The HOMO energy levels of the studied molecules in comparison with LUMO energy level of well-known acceptor material $\mathrm{PC}_{61} \mathrm{BM}$ are shown in Fig. 7.

The Voc value for compound BDD-IN with regards to $\mathrm{HOMO}_{\text {donor }}-\mathrm{LUMO}_{\mathrm{PC6} 1 \mathrm{BM}}$ energy difference is calculated to be $1.28 \mathrm{~V}$, while designed compounds with LUMOPC61BM energy difference shows higher Voc values of $1.54,1.57,1.78,1.56$ and $1.58 \mathrm{~V}$, correspondingly in comparison to the BDD-IN molecule. The smaller HOMO level of designed molecules as compared to BDD-IN is the major cause for higher value of Voc. The HOMO energy levels of DDHF-DDTC are noticed to be in following reducing order: BDDIN $>$ DDHF $>$ DDTF $>$ DMDH $>$ DDTC $>$ DMDC. The Voc value of DDHF was calculated to be $0.26 \mathrm{~V}$ which is greater than the value for BDD-IN molecule. Likewise, in DMDH, Voc was calculated to be $0.3 \mathrm{~V}$ larger as compared to the BDD-IN molecule. The largest Voc value $(1.78 \mathrm{~V})$ among all the investigated molecules is computed in case of DMDC that was found to be $0.50 \mathrm{~V}$ higher than that of BDD-IN molecule. Likewise, Voc for DDTF is calculated to be $0.28 \mathrm{~V}$ larger as compared to BDD-IN molecule and larger than DDHF but less than DMDH and DMDC molecules. Moreover, the Voc value of DDTC is calculated as $0.3 \mathrm{~V}$ higher as compared to BDD-IN molecule and greater than DDHF and DMDH molecules but less than DMDC molecule. The least value of Voc $1.54 \mathrm{~V}$ amongst all designed compounds was found in the case of DDHF which was still $0.26 \mathrm{~V}$ higher than BDD-IN $(1.28 \mathrm{~V})$ value. This investigation proves that all designed molecules DDHF-DDTC have the potential to be suitable materials for OSCs applications when blended with well-known acceptor polymer $\mathrm{PC}_{61} \mathrm{BM}$.

Charge transfer analysis. In the charge transfer (CT) investigations, a complex is established between $\mathrm{DMDC}$ and well-known acceptor polymeric materials, in this study we are using $\mathrm{PC}_{61} \mathrm{BM}$. Optimized geometry of the DMDC: $\mathrm{PC}_{61} \mathrm{BM}$ complex is shown in Fig. 8. The interactions between donor molecule DMDC and acceptor polymeric material $\mathrm{PC}_{61} \mathrm{BM}$ interact at various points, $\mathrm{C} 3$ and polymer sides are parallel. Whereas functional group side of $\mathrm{PC}_{61} \mathrm{BM}$ is positioned to the end-capped acceptor of DMDC, whereas ball side of $\mathrm{PC}_{61} \mathrm{BM}$ points toward the core side of the DMDC molecule (Fig. 8).

The electronic cloud of DMDC: $\mathrm{PC}_{61} \mathrm{BM}$ arrangement is majorly influenced by the relative positioning of the $\mathrm{DMDC}$ and $\mathrm{PC}_{61} \mathrm{BM}$ which eases the charge transformation between the electron donating and accepting parts. Dipole moment of the complex largely comes from DMDC to the acceptor and acts as the cause for effective exciton dissociation at the DMDC: $\mathrm{PC}_{61} \mathrm{BM}$ boundary ${ }^{48-50}$. The dipole moment is complex because of the electrostatic interactions of permanent dipole moment of $\mathrm{PC}_{61} \mathrm{BM}$ with respect to DMDC. Existing literature supports that the polymer part is largely responsible for the dipole moment within the complex, where, the dipole moment vector originates from the polymer side and point towards the core of the DMDC molecule. The HOMO-LUMO electronic structure and charge circulation pattern were computed at the M06/6-31G(d,p) level of DFT. The HOMO charge concentration in DMDC: $\mathrm{PC}_{61} \mathrm{BM}$ complex is concentrated on the central part and in part on the $\pi$-spacer of the donor DMDC molecule (Fig. 8b), while the LUMO charge is dispersed on end-capped group polymer $\mathrm{PC}_{61} \mathrm{BM}$ (Fig. 8b). The orbital diagram illustrates that the HOMO-to-LUMO excitation is a charge transferred from the electron donating DMDC to the electron accepting $\mathrm{PC}_{61} \mathrm{BM}$ molecule. The transformation of charge concentration from the electron donating molecule to the electron accepting is an indication of a good photovoltaic material. 

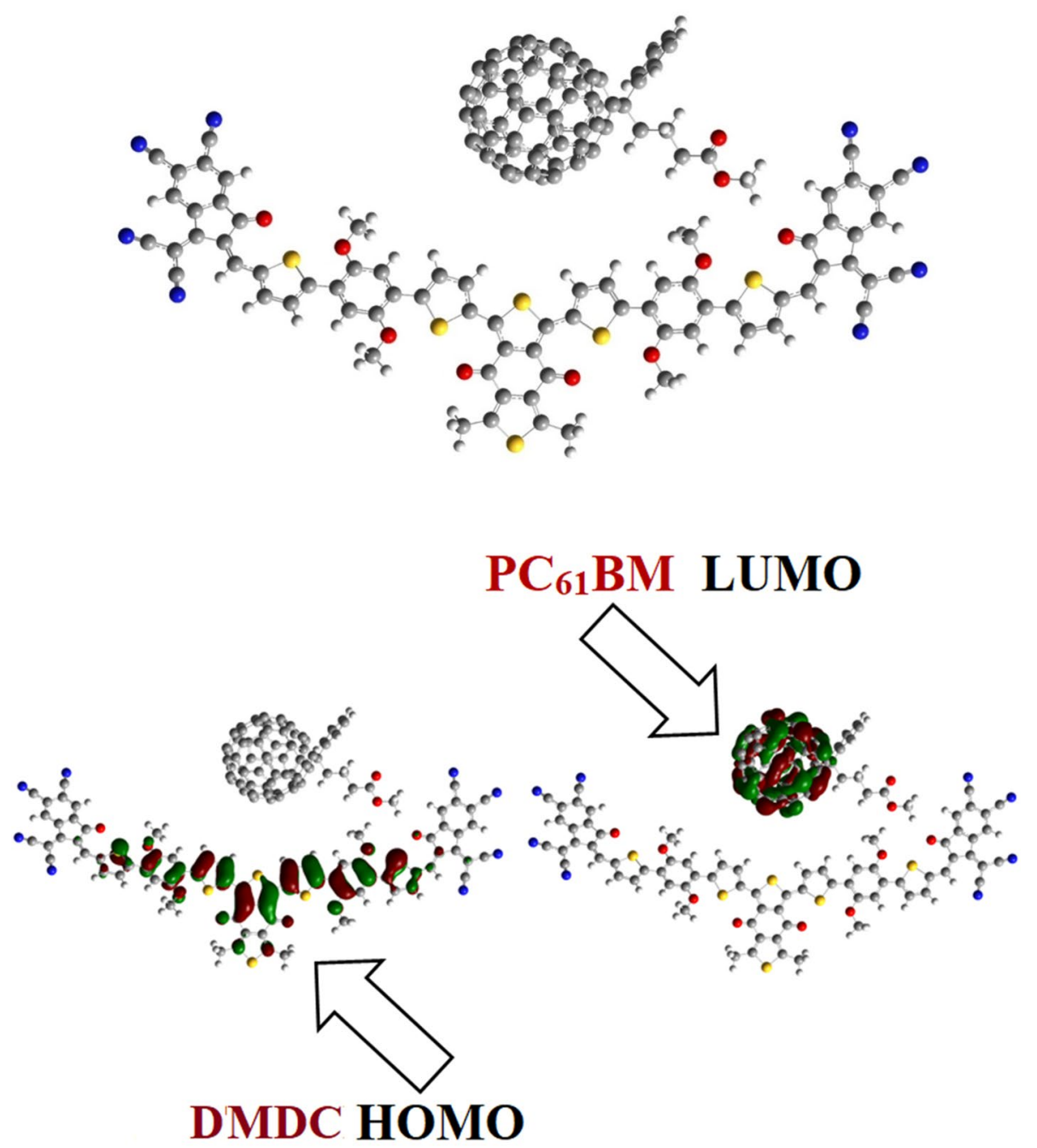

(b)

Figure 8. Graphical representation of optimized geometry of DMDC: $\mathrm{PC}_{61} \mathrm{BM}$ and Charge transfer between $\mathrm{HOMO}_{\text {donor }}$ to LUMOPC61BM. These exhibits are prepared with the help of GaussView 5.0 and Gaussian 09 version D.01 (https://gaussian.com/g09citation/).

Exciton binding energy $\left(E_{b}\right)$ and transition density matrix (TDM). The transitions nature is assessed by calculating the transition density matrixes (TDMs). The M06/6-31G (d, p) level of theory was utilized to calculate the emission and absorption of the S1 state in vacuum, the results are exhibited in Fig. 9. Due to the minute contribution in transitions, the influence of hydrogen atoms is overlooked. TDMs technique allows us to calculate, (1) the interaction within electron donating and accepting moieties in the excited state; (2) the electronic excitation (3) electron hole localization. For the determination of these properties, we distributed our studied molecules into three parts namely, acceptor-1 (A1), $\pi$-bridge (B) and acceptor-2 (A2).

The TDMs graphs designate that all compounds show analogous behavior in which electron coherence is majorly accessible on the diagonal of $\pi$-bridge segment $B$ and a minute portion is present on A1. Similarly, in case of all the designed molecules a major portion of charge is present on the end-capped acceptor A2, while in case of reference molecule BDD-IN, a minute portion is seen on A2. The electron coherence in designed molecules display similar trend that is, majorly present on the $\pi$-bridge segment $B$ and end-capped acceptor $A 2$, while a minute portion is present on A1. The TDMs graph for BDD-IN shows that major portion of electron coherence is present on the $\pi$-bridge segment $B$ and a minute portion is present on $A 1$, while a minute portion of electron coherence is seen on a diagonal of A2. From TDM diagrams, as shown in Fig. 9, the electron coherence of BDD-IN, DDHFDDTC confirm that the electrons are successfully transferred from the central acceptor A1 to the $\pi$-bridge and lastly the electron charge concentration moves to the electron acceptors. Moreover, the coefficient of interaction between donor and acceptor groups are in order of BDD-IN $>$ DMDH $>$ DDHF $>$ DDTF $>$ DDTC $>$ DMDC. This order suggests that the connection of the hole and the electrons of DMDC may be weaker as compared to the remaining studied compounds, however this exhibited greater and easier exciton dissociation in the excited state. 


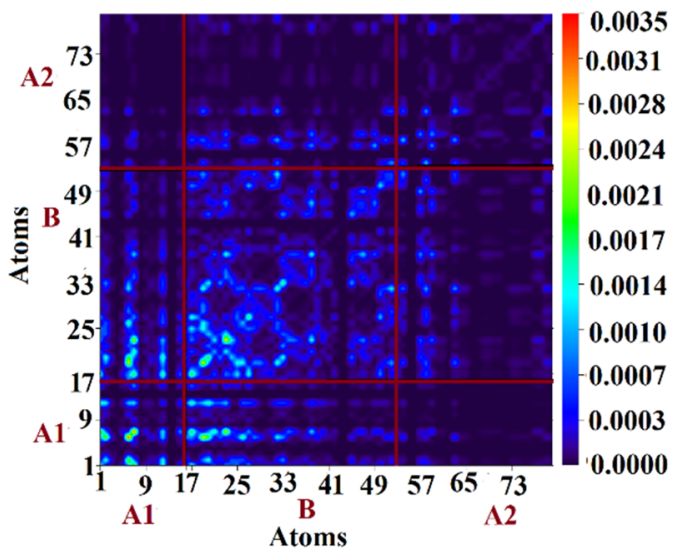

BDD-IN

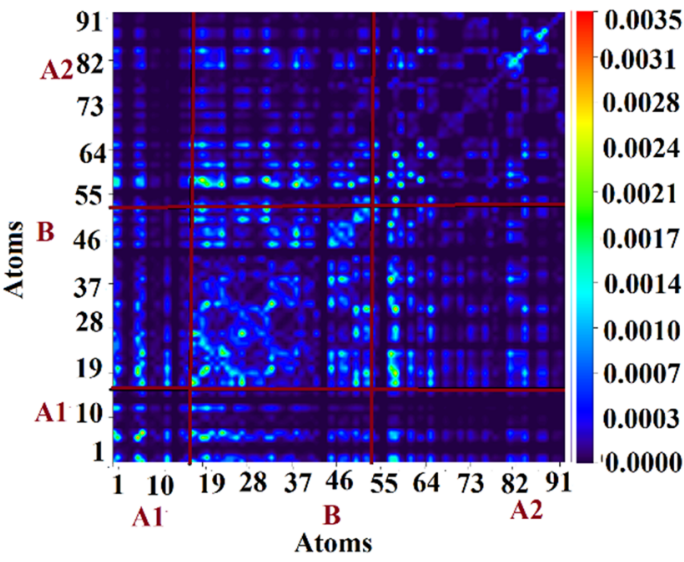

DMDH

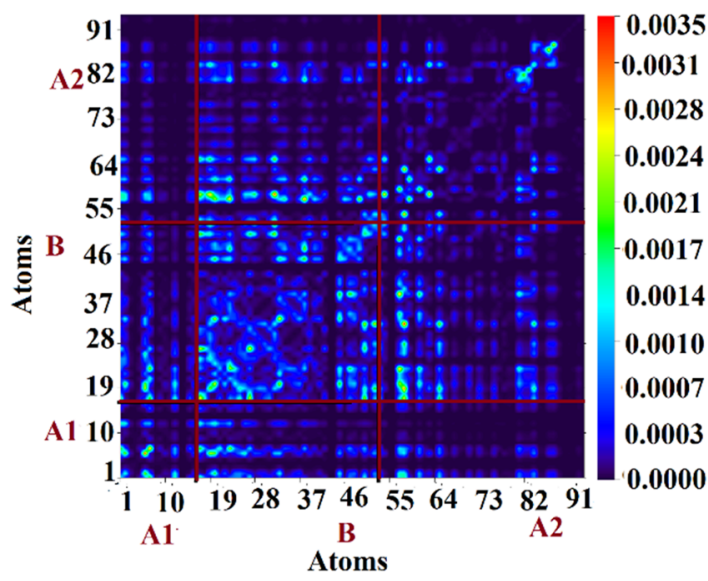

DDTF

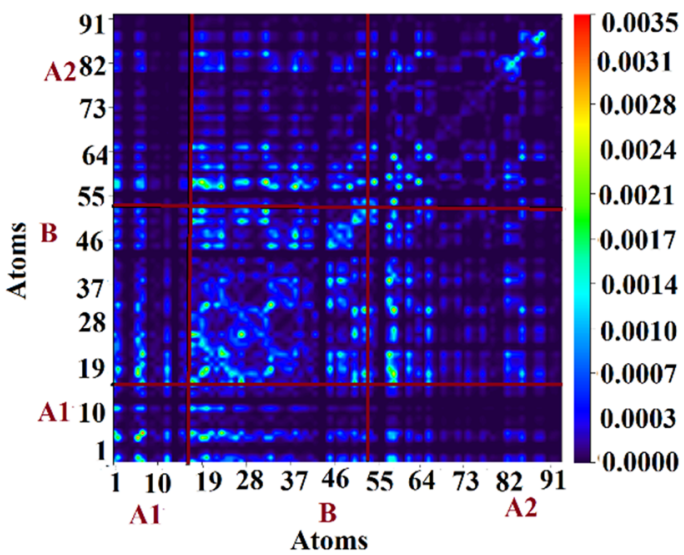

\section{DDHF}

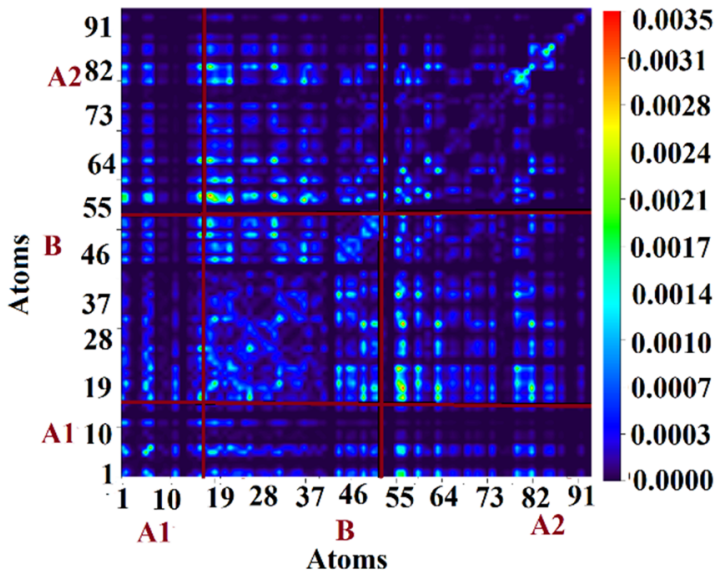

DMDC

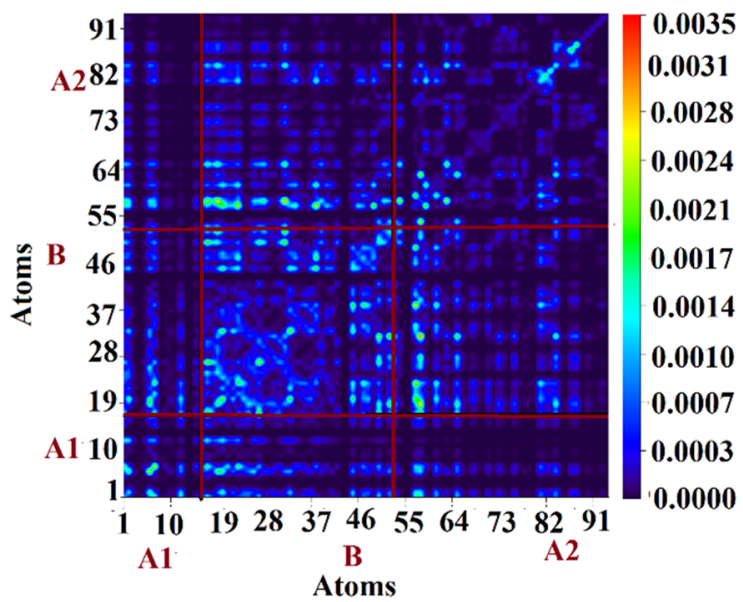

DDTC

Figure 9. Graphical representation of transition density matrix (TDM) at the S1 state. The were drawn with the help of Multiwfn 3.7 software (http://sobereva.com/multiwfn/). All out put files of designed compounds were accomplished by Gaussian 09 version D.01 (https://gaussian.com/g09citation/).

Binding energy (Eb). The binding energy profile shows that DMDC exhibit maximum charge dissociation potential of all the investigated compounds and overall the charge dissociation capability for all the designed compounds is found to be higher than that of BDD-IN molecule suggesting that designed molecules would indeed enhance the current charge concentration $(J s c)$. Binding energy $\left(E_{b}\right)$ is an important factor that supports 


\begin{tabular}{|l|l|l|l|}
\hline Molecule & Е $_{\text {Hомо-LUMо }}(\mathbf{e V})$ & $\mathbf{E}_{\mathbf{p p t i}}(\mathbf{e V})$ & $\mathbf{E}_{\text {binding }}(\mathbf{e V})$ \\
\hline BDD-IN & 2.34 & 2.11 & 0.23 \\
\hline DDHF & 2.39 & 1.86 & 0.53 \\
\hline DMDH & 2.35 & 1.81 & 0.54 \\
\hline DMDC & 2.17 & 1.69 & 0.48 \\
\hline DDTF & 2.34 & 1.82 & 0.52 \\
\hline DDTC & 2.31 & 1.79 & 0.52 \\
\hline
\end{tabular}

Table 4. Calculated $\mathrm{E}_{\mathrm{H}-\mathrm{L}}, \mathrm{E}_{\mathrm{opt}}$, and $\mathrm{E}_{\mathrm{b}}$ of BDD-IN, DDHF-DDTC.

the assessment of the optoelectronic properties of OCs. Binding energy enables us to calculate the interaction of the columbic forces among the hole and electron. The $E_{b}$ and columbic interaction of the hole and electron are directly proportional with each other and both have inverse relation with exciton dissociation in the excited state. $E_{b}$ of BDD-IN, DDHF-DDTC molecules are calculated by utilizing the following Eq. (4).

$$
E_{b}=E_{\mathrm{H}-\mathrm{L}}-E_{\mathrm{opt}}
$$

In Eq. (2), $\mathrm{E}_{\mathrm{HOMO}-\mathrm{LUMO}}$ signifies energy difference of HOMO/LUMO and $\mathrm{E}_{\mathrm{opt}}$ shows that the smallest quantity of energy required for the first excitation (gained from $S_{0}$ to $S_{1}$ ), by producing pair of the electron and hole ${ }^{51,52}$. Calculated results for binding energy $\left(E_{b}\right)$ are arranged in Table 4.

The $\mathrm{E}_{\mathrm{b}}$ value of $\mathrm{BDD}-\mathrm{IN}$ molecule is $0.23 \mathrm{eV}$ and it is exciting to note that the binding energy $\left(\mathrm{E}_{\mathrm{b}}\right)$ values of DDHF-DDTC molecules, higher in comparison to the BDD-IN molecule, are found to be 0.53 , $0.54,0.48,0.52$ and $0.52 \mathrm{eV}$ correspondingly. Descending order of $E_{b}$ values for investigated compounds is DDTC $>$ DMDH $>$ DDHF $>$ DDTF $>$ DMDC $>$ BDD-IN. These results with maximum $E_{b}$ value of DDHF-DDTC molecules and minimum $E_{b}$ value of BDD-IN molecule are in good agreement with TDMs.

\section{Conclusions}

A series of new non-fullerene donors (DDHF-DDTC) are designed keeping in view a synthesized non-fullerenebased electron donor molecule (BDD-IN) with Acceptor- $\pi$-Acceptor- $\pi$-Acceptor (A- $\pi$-A- $\pi-A)$ configuration using different end-capped electron accepting groups. The optoelectronic properties of designed compounds are found to be better than that of BDD-IN molecule. The designed and reference compounds exhibited lower energy difference in the region of $2.17-2.39 \mathrm{eV}$ and $2.72 \mathrm{eV}$, respectively and revealed that results of designed compounds are better than that of the reference molecule. Interestingly, DMDC exhibited the smaller energy difference of $2.17 \mathrm{eV}$ value which is obtained less in magnitude than designed molecules as well as BDD-IN molecule due to the strong electron withdrawing effect of the end-capped acceptor. Moreover, DDHF-DDTC molecules exhibited red shifted $\lambda_{\text {max }}$ in visible range with $666-732 \mathrm{~nm}$ values in comparison to BDD-IN (585 nm). Similarly, to energy difference pattern, DMDC is reported with smaller transition energy value $(1.69 \mathrm{eV})$ along with absorption peak value as $732 \mathrm{~nm}$. Open circuit voltage (Voc) with respect to the $\mathrm{HOMO}_{\text {Donor }}-\mathrm{LUMO}_{\mathrm{PC} 61 \mathrm{BM}}$ of DDHF-DDTC, are found in the region of 1.54-1.78 V markedly greater when compared with BDD-IN (Voc $=1.28 \mathrm{~V})$. DMDC molecule is the promising candidate as consisting of the lower values of $\lambda_{\mathrm{e}}$ and $\lambda_{\mathrm{h}}$ transportation: $\lambda_{\mathrm{e}}(0.00285$ $\left.E_{h}\right)$ and $\lambda_{\mathrm{h}}\left(0.00847 E_{h}\right)$ among all the investigated compounds. Finally, among all DDHF-DDTC, the designed molecule DMDC presented exceptional optoelectronic properties because of the strong electron withdrawing effect of the end-capped acceptor tetra-cyano combined with extended conjugation. Overall, DDHF-DDTC are appropriate donor moieties for their usage in the OSCs applications.

\section{Materials and methods}

Gaussian 09 package ${ }^{53}$ was utilized to perform the calculations. Initially, GaussView 5.0 program ${ }^{54}$ was used to yield three dimensional structures of the molecules and input files for Gaussian 09 package. The geometry optimization of BDD-IN molecule was executed by six DFT based functionals: B3LYP ${ }^{55}$, CAM-B3LYP ${ }^{56}$, MPW1PW91 ${ }^{57}$, $\omega \mathrm{B} 97 \mathrm{XD}^{58}{ }^{\mathrm{L}} \mathrm{LC}-\mathrm{BLYP}^{59}$ and M06 ${ }^{60}$ along with $6-31 \mathrm{G}(\mathrm{d}, \mathrm{p})$ basis set. Later, structural optimization using frequency analysis at true minima of potential energy surface, TD-DFT calculations were employed for calculating the absorption spectra $\left(\lambda_{\max }\right)$ of BDD-IN molecule at same levels of theory and basis set combinations. Among all tested functionals, $\lambda_{\max }$ result of $\mathrm{M} 06 / 6-31 \mathrm{G}(\mathrm{d}, \mathrm{p})$ functional was found in agreement to the experimental $\lambda_{\max }$ results for BDD-IN molecule. Therefore, M06/6-31G(d,p) level of theory was considered ideal to be used in this study for computing density of state (DOS), TDM surfaces, FMO analysis, reorganization energies, charge transfer analysis, open circuit voltage $\left(\mathrm{V}_{\mathrm{oc}}\right)$, and band gap of BDD-IN as well as designed DDHF, DMDH, DMDC, DDTF and DDTC compounds. The chloroform solvent with conductor-like polarizable continuum (CPCM) model ${ }^{61}$ was utilized for estimating $\lambda_{\max }$ values of the investigated compounds.

Reorganization energy was also computed at M06/6-31G (d, p) level of theory. External $\left(\lambda_{\text {ext }}\right)$ reorganization energy specifies external environmental relaxation, while internal $\left(\lambda_{\text {int }}\right)$ reorganization energy gives the glance of quick changes in internal composition. In this study only internal environmental effects were focused, and electron $\left(\lambda_{\mathrm{e}}\right)$, hole $\left(\lambda_{\mathrm{h}}\right)$ energies were computed employing Eqs. (3) and $(4)^{62-64}$.

$$
\lambda_{e}=\left[E_{0}^{-}-E_{-}\right]+\left[E_{-}^{0}+E_{0}\right]
$$




$$
\lambda_{\mathrm{h}}=\left[E_{0}^{+}-E_{+}\right]+\left[E_{+}^{0}-E_{0}\right]
$$

where $E_{0}^{-}$and $E_{0}^{+}$are anionic and cationic energies obtained through optimized structures of neutral molecule, while $E_{-}^{0}$ and $E_{+}^{0}$ are molecular energies of neutral molecule calculated at anionic and cationic states. $E_{+}$and $E_{-}$indicate the optimized energies for anionic and cationic structures. $E_{0}$ specifies single point ground state energy $^{46}$. The Swizard ${ }^{65}$, PyMOlyze $2.0^{66}$, Multiwfn $3.7^{67}$, Origin 8.0, Avogadro ${ }^{68}$ and Chemcraft ${ }^{69}$ programs were used to analyse data.

Received: 12 August 2021; Accepted: 17 September 2021

Published online: 02 November 2021

\section{References}

1. Nilsson, M., Lucas, P. \& Yoshida, T. Towards an integrated framework for SDGs: Ultimate and enabling goals for the case of energy. Sustainability 5(10), 4124-4151 (2013).

2. Kumar, M. \& Kumar, A. Performance assessment and degradation analysis of solar photovoltaic technologies: A review. Renew. Sustain. Energy Rev. 78, 554-587 (2017).

3. Shahsavari, A. \& Akbari, M. Potential of solar energy in developing countries for reducing energy-related emissions. Renew. Sustain. Energy Rev. 90, 275-291 (2018).

4. Chandramohan, S., Janardhanam, V., Seo, T. H., Hong, C.-H. \& Suh, E.-K. Improved photovoltaic effect in graphene/silicon solar cell using $\mathrm{MoO} 3 / \mathrm{Ag} / \mathrm{MoO} 3$ multilayer coating. Mater. Lett. 246, 103-106 (2019).

5. R.F. Service. Outlook Brightens for Plastic Solar Cells (American Association for the Advancement of Science, 2011).

6. Cui, Y. et al. Achieving over 15\% efficiency in organic photovoltaic cells via copolymer design. Adv. Mater. 31(14), 1808356 (2019).

7. Meng, L. et al. Organic and solution-processed tandem solar cells with 17.3\% efficiency. Science 361(6407), 1094-1098 (2018).

8. Kan, B. et al. A chlorinated low-bandgap small-molecule acceptor for organic solar cells with $14.1 \%$ efficiency and low energy loss. Sci. China Chem. 61(10), 1307-1313 (2018).

9. Collins, S. D., Ran, N. A., Heiber, M. C. \& Nguyen, T. Q. Small is powerful: recent progress in solution-processed small molecule solar cells. Adv. Energy Mater. 7(10), 1602242 (2017).

10. Roncali, J., Leriche, P. \& Blanchard, P. Molecular materials for organic photovoltaics: small is beautiful. Adv. Mater. 26(23), 3821-3838 (2014).

11. Huo, Y. et al. Dual-accepting-unit design of donor material for all-small-molecule organic solar cells with efficiency approaching 11\%. Chem. Mater. 30(23), 8661-8668 (2018).

12. Kan, B. et al. Asymmetrical side-chain engineering of small-molecule acceptors enable high-performance nonfullerene organic solar cells. Nano Energy 67, 104209 (2020).

13. Kan, B. et al. A series of simple oligomer-like small molecules based on oligothiophenes for solution-processed solar cells with high efficiency. J. Am. Chem. Soc. 137(11), 3886-3893 (2015).

14. Ni, W., Wan, X., Li, M., Wang, Y. \& Chen, Y. A-D-A small molecules for solution-processed organic photovoltaic cells. Chem. Commun. 51(24), 4936-4950 (2015).

15. Chen, W. \& Zhang, Q. Recent progress in non-fullerene small molecule acceptors in organic solar cells (OSCs). J. Mater. Chem. C 5(6), 1275-1302 (2017).

16. Sun, H. et al. PDI derivative through fine-tuning the molecular structure for fullerene-free organic solar cells. ACS Appl. Mater. Interfaces 9(35), 29924-29931 (2017).

17. Kan, B. et al. Solution-processed organic solar cells based on dialkylthiol-substituted benzodithiophene unit with efficiency near 10\%. J. Am. Chem. Soc. 136(44), 15529-15532 (2014).

18. Deng, D. et al. Fluorination-enabled optimal morphology leads to over $11 \%$ efficiency for inverted small-molecule organic solar cells. Nat. Commun. 7(1), 1-9 (2016).

19. Xin, R. et al. Nonfullerene-acceptor all-small-molecule organic solar cells based on highly twisted perylene bisimide with an efficiency of over 6\%. ACS Appl. Mater. Interfaces 9(3), 2739-2746 (2017).

20. Yang, L. et al. New wide band gap donor for efficient fullerene-free all-small-molecule organic solar cells. J. Am. Chem. Soc. 139(5), 1958-1966 (2017).

21. He, X., Yin, L. \& Li, Y. Design of organic small molecules for photovoltaic application with high open-circuit voltage (Voc). J. Mater. Chem. C 7(9), 2487-2521 (2019).

22. Adhikari, T., Nunzi, J.-M. \& Lebel, O. Towards amorphous solution-processed small-molecule photovoltaic cells by design. Org. Electron. 49, 382-392 (2017).

23. Adhikari, T. et al. T-Shaped Indan-1,3-dione derivatives as promising electron donors for bulk heterojunction small molecule solar cell. Opt. Mater. 69, 312-317 (2017).

24. Ie, Y., Huang, J., Uetani, Y., Karakawa, M. \& Aso, Y. Synthesis, properties, and photovoltaic performances of donor-acceptor copolymers having dioxocycloalkene-annelated thiophenes as acceptor monomer units. Macromolecules 45(11), 4564-4571 (2012).

25. Zhao, W. et al. Fullerene-free polymer solar cells with over $11 \%$ efficiency and excellent thermal stability. Adv. Mater. 28(23), 4734-4739 (2016).

26. Zhang, Q. et al. An A 2- $\pi-\mathrm{A} 1-\pi-\mathrm{A} 2$-type small molecule donor for high-performance organic solar cells. J. Mater. Chem. C 7(18), 5381-5384 (2019)

27. Khan, M. U. et al. Novel W-shaped oxygen heterocycle-fused fluorene-based non-fullerene acceptors: first theoretical framework for designing environment-friendly organic solar cells. Energy Fuels 35(15), 12436-12450 (2021).

28. Khan, M. U. et al. In silico modeling of new "Y-Series"-based near-infrared sensitive non-fullerene acceptors for efficient organic solar cells. ACS Omega 5(37), 24125-24137 (2020).

29. Khan, M. U. et al. Molecular designing of high-performance 3D star-shaped electron acceptors containing a truxene core for nonfullerene organic solar cells. J. Phys. Org. Chem. 34(1), e4119 (2021).

30. Khan, M. U. et al. Designing spirobifullerene core based three-dimensional cross shape acceptor materials with promising photovoltaic properties for high-efficiency organic solar cells. Int. J. Quantum Chem. 120(22), e26377 (2020).

31. Khan, M. U. et al. First theoretical framework of Z-shaped acceptor materials with fused-chrysene core for high performance organic solar cells. Spectrochim. Acta A Mol. Biomol. Spectrosc. 245, 118938 (2021).

32. Khan, M. U. et al. Molecular designing of high-performance 3D star-shaped electron acceptors containing a truxene core for nonfullerene organic solar cells. J. Phys. Org. Chem. 34, e4119 (2020).

33. Hussain, R. et al. Molecular engineering of A-D-C-D-A configured small molecular acceptors (SMAs) with promising photovoltaic properties for high-efficiency fullerene-free organic solar cells. Opt. Quant. Electron. 52(8), 1-20 (2020).

34. Mehboob, M. Y. et al. Designing N-phenylaniline-triazol configured donor materials witsh promising optoelectronic properties for high-efficiency solar cells. Comp. Theor. Chem. 56, 112908 (2020). 
35. Khan, M. U. et al. Designing spirobifullerene core based three-dimensional cross shape acceptor materials with promising photovoltaic properties for high-efficiency organic solar cells. Int. J. Quantum Chem. 26, e26377 (2020).

36. Shehzad, R. A. et al. Designing of benzothiazole based non-fullerene acceptor (NFA) molecules for highly efficient organic solar cells. Comp. Theor. Chem. 1181, 112833 (2020).

37. Janjua, M. R. S. A. et al. Theoretical and conceptual framework to design efficient dye-sensitized solar cells (DSSCs): molecular engineering by DFT method. J. Clust. Sci. 32, 243-253 (2020).

38. Khan, M. U. et al. First theoretical framework of triphenylamine-dicyanovinylene-based nonlinear optical dyes: Structural modification of $\pi$-linkers. J. Phys. Chem. C 122(7), 4009-4018 (2018).

39. Janjua, M. R. S. A. et al. Effect of $\pi$-conjugation spacer (C C) on the first hyperpolarizabilities of polymeric chain containing polyoxometalate cluster as a side-chain pendant: A DFT study. Comp. Theor. Chem. 994, 34-40 (2012).

40. Janjua, M. R. S. A. et al. A DFT study on the two-dimensional second-order nonlinear optical (NLO) response of terpyridinesubstituted hexamolybdates: physical insight on 2D inorganic-organic hybrid functional materials. Eur. J. Inorg. Chem. 2012(4), 705-711 (2012).

41. Khan, M. U. et al. First theoretical probe for efficient enhancement of nonlinear optical properties of quinacridone based compounds through various modifications. Chem. Phys. Lett. 715, 222-230 (2019).

42. Khan, M. U. et al. Prediction of second-order nonlinear optical properties of D-p-A compounds containing novel fluorene derivatives: a promising route to giant hyperpolarizabilities. J. Clust. Sci. 30(2), 415-430 (2019).

43. Khan, M. U. et al. Quantum chemical designing of indolo [3, 2, 1-jk] carbazole-based dyes for highly efficient nonlinear optical properties. Chem. Phys. Lett. 719, 59-66 (2019).

44. Amiri, S. S., Makarem, S., Ahmar, H. \& Ashenagar, S. Theoretical studies and spectroscopic characterization of novel 4-methyl5-((5-phenyl-1, 3, 4-oxadiazol-2-yl) thio) benzene-1, 2-diol. J. Mol. Struct. 1119, 18-24 (2016).

45. Irfan, M. et al. Design of donor-acceptor-donor (D-A-D) type small molecule donor materials with efficient photovoltaic parameters. Int. J. Quantum Chem. 117(10), e25363 (2017).

46. Tang, S. \& Zhang, J. Design of donors with broad absorption regions and suitable frontier molecular orbitals to match typical acceptors via substitution on oligo (thienylenevinylene) toward solar cells. J. Comput. Chem. 33(15), 1353-1363 (2012).

47. Scharber, M. C. et al. Design rules for donors in bulk-heterojunction solar cells-Towards $10 \%$ energy-conversion efficiency. Adv. Mater. 18(6), 789-794 (2006).

48. Arkhipov, V., Heremans, P. \& Bässler, H. Why is exciton dissociation so efficient at the interface between a conjugated polymer and an electron acceptor?. Appl. Phys. Lett. 82(25), 4605-4607 (2003).

49. Marchiori, C. \& Koehler, M. Dipole assisted exciton dissociation at conjugated polymer/fullerene photovoltaic interfaces: A molecular study using density functional theory calculations. Synth. Met. 160(7-8), 643-650 (2010).

50. Koehler, M., Santos, M. \& Da Luz, M. Positional disorder enhancement of exciton dissociation at donor/acceptor interface. J. Appl. Phys. 99(5), 053702 (2006).

51. Köse, M. E. Evaluation of acceptor strength in thiophene coupled donor-acceptor chromophores for optimal design of organic photovoltaic materials. J. Phys. Chem. A 116(51), 12503-12509 (2012).

52. Dkhissi, A. Excitons in organic semiconductors. Synth. Met. 161(13-14), 1441-1443 (2011).

53. M.J. Frisch, G.W. Trucks, H.B. Schlegel, G. Scuseria, M.A. Robb, J.R. Cheeseman, G. Scalmani, V. Barone, B. Mennucci, G. Petersson, H. Nakatsuji, M. Caricato, X. Li, H.P. Hratchian, A.F. Izmaylov, J. Bloino, G. Zheng, J.L. Sonnenberg, M. Hada, M. Ehara, K. Toyota, R. Fukuda, J. Hasegawa, M. Ishida, T. Nakajima, Y. Honda, O. Kitao, H. Nakai, T. Vreven, J.A. Montgomery, J.E. Peralta, F. Ogliaro, M. Bearpark, J.J. Heyd, E. Brothers, K.N. Kudin, V.N. Staroverov, R. Kobayashi, J. Normand, K. Raghavachari, A. Rendell, J.C. Burant, S.S. Iyengar, J. Tomasi, M. Cossi, N. Rega, J.M. Millam, M. Klene, J.E. Knox, J.B. Cross, V. Bakken, C. Adamo, J. Jaramillo, R. Gomperts, R.E. Stratmann, O. Yazyev, A.J. Austin, R. Cammi, C. Pomelli, J.W. Ochterski, R.L. Martin, K. Morokuma, V.J. Zakrzewski, G.A. Voth, P. Salvador, J.J. Dannenberg, S. Dapprich, A.D. Daniels, O. Farkas, J.B. Foresman, J.V. Ortiz, J. Cioslowski, D.J. Fox, D. 0109, Revision D. 01, Gaussian, Inc., Wallingford, CT (2009).

54. R.D. Dennington, T.A. Keith, J.M. Millam, GaussView 5.0. 8, Gaussian Inc (2008).

55. Civalleri, B., Zicovich-Wilson, C. M., Valenzano, L. \& Ugliengo, P. B3LYP augmented with an empirical dispersion term (B3LYP$\mathrm{D}^{*}$ ) as applied to molecular crystals. CrystEngComm 10(4), 405-410 (2008).

56. Yanai, T., Tew, D. P. \& Handy, N. C. A new hybrid exchange-correlation functional using the Coulomb-attenuating method (CAMB3LYP). Chem. Phys. Lett. 393(1-3), 51-57 (2004).

57. Adamo, C. \& Barone, V. Exchange functionals with improved long-range behavior and adiabatic connection methods without adjustable parameters: The $\mathrm{m}$ PW and m PW1PW models. J. Chem. Phys. 108(2), 664-675 (1998).

58. Chai, J.-D. \& Head-Gordon, M. Long-range corrected hybrid density functionals with damped atom-atom dispersion corrections. Phys. Chem. Chem. Phys. 10(44), 6615-6620 (2008).

59. Iikura, H., Tsuneda, T., Yanai, T. \& Hirao, K. A long-range correction scheme for generalized-gradient-approximation exchange functionals. J. Chem. Phys. 115(8), 3540-3544 (2001).

60. Zhao, Y. \& Truhlar, D. G. The M06 suite of density functionals for main group thermochemistry, thermochemical kinetics, noncovalent interactions, excited states, and transition elements: two new functionals and systematic testing of four M06-class functionals and 12 other functionals. Theor. Chem. Acc. 120(1-3), 215-241 (2008).

61. Barone, V. \& Cossi, M. Quantum calculation of molecular energies and energy gradients in solution by a conductor solvent model. J. Phys. Chem. A 102(11), 1995-2001 (1998).

62. Khan, M. U. et al. Designing triazatruxene-based donor materials with promising photovoltaic parameters for organic solar cells. RSC Adv. 9(45), 26402-26418 (2019).

63. Hussain, R. et al. Enhancement in photovoltaic properties of N, N-diethylaniline based donor materials by bridging core modifications for efficient solar cells. ChemistrySelect 5(17), 5022-5034 (2020).

64. Afzal, Z. et al. Designing indenothiophene-based acceptor materials with efficient photovoltaic parameters for fullerene-free organic solar cells. J. Mol. Model. 26(6), 137-137 (2020).

65. S. Gorelsky, SWizard Program, University of Ottawa, Ottawa, Canada, 2010, There is no corresponding record for this reference (2013).

66. O'boyle, N. M., Tenderholt, A. L. \& Langner, K. M. Cclib: a library for package-independent computational chemistry algorithms. J. Comput. Chem. 29(5), 839-845 (2008).

67. Lu, T. \& Chen, F. Multiwfn: a multifunctional wavefunction analyzer. J. Comput. Chem. 33(5), 580-592 (2012).

68. Hanwell, M. D. et al. Avogadro: an advanced semantic chemical editor, visualization, and analysis platform. J. Cheminform. 4(1), 17 (2012).

69. G.A. Andrienko, Chemcraft. Graphical Software for Visualization of Quantum Chemistry Computations, 2010.

\section{Acknowledgements}

M. M. A and M. I. express appreciation to the Deanship of Scientific Research at King Khalid University Saudi Arabia through a research groups program under Grant Number R.G.P. 1/356/42. A.A.C.B. (Grants 2015/01491-3 and 2014/25770-6) is thankful to Fundacão de Amparo à Pesquisa do Estado de Sao Paulo for financial support. A.A.C.B. (Grant 312550/2020-0) also thanks the Brazilian National Research Council (CNPq) for financial 
support and fellowships. This study was financed in part by the Coordenação de Aperfeiçoamento de Pessoal de Nivel Superior do Brasil (CAPES) Finance Code 001.

\section{Author contributions}

Conceptualization, MK, MUK and MSA.; methodology, MK, MUK, ZS and SA.; software, MMA, AACB, MSA; validation, MK, MI, MSA; formal analysis, MK, MUK, MI ; investigation MK, MUK, MI.; writing—original draft preparation, MK, MUK; Final version writing - review and editing, MSA, MK ; visualization, AACB; funding acquisition, MMA, MI, AACB. All authors have read and agreed to the published version of the manuscript.

\section{Competing interests}

The authors declare no competing interests.

\section{Additional information}

Supplementary Information The online version contains supplementary material available at https://doi.org/ 10.1038/s41598-021-01070-3.

Correspondence and requests for materials should be addressed to M.U.K., Z.S. or M.S.A.

Reprints and permissions information is available at www.nature.com/reprints.

Publisher's note Springer Nature remains neutral with regard to jurisdictional claims in published maps and institutional affiliations.

(c) Open Access This article is licensed under a Creative Commons Attribution 4.0 International License, which permits use, sharing, adaptation, distribution and reproduction in any medium or format, as long as you give appropriate credit to the original author(s) and the source, provide a link to the Creative Commons licence, and indicate if changes were made. The images or other third party material in this article are included in the article's Creative Commons licence, unless indicated otherwise in a credit line to the material. If material is not included in the article's Creative Commons licence and your intended use is not permitted by statutory regulation or exceeds the permitted use, you will need to obtain permission directly from the copyright holder. To view a copy of this licence, visit http://creativecommons.org/licenses/by/4.0/.

(C) The Author(s) 2021 